\author{
UNIVERSIDADE DE SÃO PAULO \\ FACULDADE DE CIENNCIAS FARMACÊUTICAS \\ Programa de Pós-Graduação em Ciência dos Alimentos \\ Área de Nutrição Experimental
}

\title{
LDL ELETRONEGATIVA EM PACIENTES RENAIS CRÔNICOS SOB HEMODIÁLISE E DIÁLISE PERITONEAL E SUA RELAÇÃO COM O ESTADO NUTRICIONAL
}

JULIE CALIXTO LOBO

Dissertação para obtenção do grau de MESTRE

Orientadora:

Prof ${ }^{\text {a }}$ Dr ${ }^{\mathrm{a}}$. Dulcinéia Saes Parra Abdalla

Såo Paulo

2007 
JULIE CALIXTO LOBO

\section{LDL ELETRONEGATIVA EM PACIENTES RENAIS CRÔNICOS SOB HEMODIÁLISE E DIÁLISE PERITONEAL E SUA RELAÇÃO COM O ESTADO NUTRICIONAL}

Universidade de São Paulo

Departamento de Alimentos e Nutrição Experimental

Dissertação de Mestrado

Orientadora: Prof ${ }^{a}$. Dr ${ }^{a}$. Dulcinéia Saes Parra Abdalla

São Paulo 


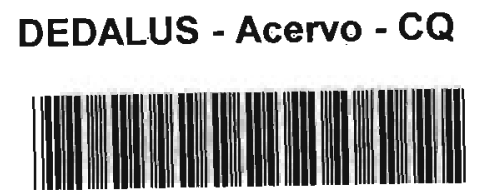

30100013307

Ficha Catalográfica

Elaborada pela Divisão de Bibliteca e

Documentação do conjunto das Químicas da USP.

Lobo, Julie Calixto

L799L LDL eletronegativa em pacientes renais crônicos sob hemodiálise e diálise peritoneal e sua relação com o estado nutricional / Julie Calixto Lobo. -- São Paulo, 2007.

$80 \mathrm{p}$.

Dissertação (mestrado) - Faculdade de Ciências Farmacêuticas da Universidade de São Paulo. Departamento de Alimentos e Nutrição Experimental.

Orientador: Abdalla. Dulcinéia Saes Parra

1. Nutrição : Ciências dos alimentos 2. Rins : Medicina 3. Bioquímica clínica : Medicina I. T. II. Abdalla, Dulcinéia Saes Parra, orientador. 
JULIE CALIXTO LOBO

\title{
LDL ELETRONEGATIVA EM PACIENTES RENAIS CRÔNICOS SOB HEMODIÁLISE E DIÁLISE PERITONEAL E SUA RELAÇÃO COM O ESTADO NUTRICIONAL
}

\author{
Comissăo Julgadora \\ da \\ Dissertaçăo para obtençăo do grau de Mestre \\ Prof?. Drª . Dulcinéia Saes Parra Abdalla \\ orientadora/presidente \\ $1^{\circ}$. examinador \\ $2^{\circ}$. examinador
}

São Paulo, Setembro de 2007.

13 de molentio nont 
"Para ser grande, sê inteiro: nada Teu exagera ou exclui. Sê todo em cada coisa. Põe quanto és No mínimo que fazes. Assim em cada lago a lua toda Brilha, porque alta vive." (Fernando pessoa) 
Dedico esta dissertação ...

A minha mãezona, coisa mais querida da minha vida, parceira, amiga, amor incondicional, que bom que tenho um tanto de você em mim!!!!

Aos pacientes que participaram da pesquisa, por terem sido tão fofos, por todos os sorrisos que encontrei apesar das agultradas, muito obrigada e que vocês sajam muito felizes. 


\section{Agradecimentos}

A CAPES pelo auxilio financeiro concedido.

A FCF-USP/Departamento de Alimentos e Nutrição experimental pela oportunidade da pós-graduação.

Ao Laboratório de Análises Clínica-USP (BL 17), por ser o meu lugar durante o mestrado.

A grande sábia, Profa Dra Titular Dulcinéia Saes Parra Abdalla, um dia quero saber um terço do que você sabe, MUITO OBRIGADA por tudo! Sentirei saudades!!!

À minha Co-orientadora, ou melhor, Colaboradora Profa Dra Denise Mafra (UFF), por todas as oportunidades, por acreditar em mim, por ser minha amiga, te amo muito!!!! Muito obrigada sempre Guria!!!

Ao Prof. Dr. Maurilo de Narazé de Lima Leite Junior, muito obrigada pela clínica, ela atenção, pelas sugestões, por todo o carinho.

Aos professores da UFF por terem me apoiado, por me incentivarem, devo muito a vocês!! Em especial ao professor Gilson que nos cedeu o laboratório e a Solange por ter coletado os sanguinhos do grupo controle.

A todos os funcionários da clinica, muitoooooo obrigada por me deixarem invadir o espaço de vocês!!! Em especial a Jane que nos ajudou bastante nas coletas e a assistente social Thiana por ter sido nosso braço direito!

Mônica, Jorge e Elaine, muito obrigada pela ajuda!!! 
Aos amigos do laboratório: Andréa (sentirei saudades!), Cris (Obrigada pelo carinho!), Tanize (Tivemos pouco contato, mas obrigada pelas ajudas nos ELISAS e nos contatos virtuais), Simone (muito obrigada pela ajuda nos experimentos e por me acolher no seu apê!), Martina (saudades de você!), Renato (vai sentir saudade da sua amiga "carica", né?), Evelyne (saudades dos biscoitos da sua mãe, hummm!!! Obrigada pela ajuda!), Laila (amiga te devo a alma!!!Você sempre foi maravilhosa comigo, quero que nossa amizade dure pra sempre!!! Te amo!) Dani (minha praticamente segunda coorientadora, você é incrivel, te devo a alma ao cubo, muitoooo obrigada por tudo, sei que não vamos sumir uma da outra), Themis (Nossa morro de saudades, obrigada pelo apoio no inicio desse trabalho, você foi maravilhosa!)

Mau, queridoooo0000000, esse aturou meus estresses, nossaaaaa!!!! Muito obrigada por lutar comigo no HPLC, por todo o carinho, pelas risadas, por tudo, você é incrivel!!!!

Lana e Gabi, muitoooooooo obrigada por me acolherem no crusp, obrigada pelos momentos de descontração, pelas risadas mil, pelos desabafos, por tudo!!! Vocês são lindas!!!!! Déa, obrigada por me ceder seu quarto eventualmente, por me acolher!

Karê e Lu, muito obrigada pelo apoio de vocês!!!

Chico querido, nossaaaaaa muito obrigada, pela amizade, pelo carinho, pela paciência quando eu chorava de desespero que as coisas davam erradas, você foi meu anjo da guarda!!

Ao meu amigãoooo Felipe, por participar de tudo desde que nos conhecenos, ainda bem que você existe, o que seria de mim sem você? Te amo!!!

À Sida, pelas comidinhas deliciosas e por sempre me chamar pra tomar café quando eu já não agüentava mais estudar.

À minha irmã de ventre diferente, Aminne, amo você muito!!!! 
A Carol, Eveline, Gabriela, Érika, Pri e Zizi, amigas vocês são maravilhosas, amo vocês!!!

Aos amigos da faculdade Ana, Chris Bin, "bubu", Ju, Marluce, "Sarandon", Giselle, "Patis", "Fetz", Alicia, desculpa de esqueci de alguém (saudades de vocês!!!!).

A galera do Vila Magna, saudades do tempo em que éramos crianças e podiamos ficar perto uns dos outros brincando sem ver o tempo passar, era só felicidade!!!

A minha família, meu pai (que mesmo não entendendo muito o que eu faço, sempre me apoiou, te amo!!!), minha irmã, minhas avós lindas!, minha tia Nilce, tia "nês", meus primos queridos Isabella e Matheus, Marcelo (obrigada por escutar mirihas coisas e por levantar minha bola!!!), ao meu avô Else (mesmo que no momento ele não esteja mais conosco, ele ia gostar de me ver agora!) Amo vocês demais!!!

A Tereza e Antonio Sérgio por terem colocado o Antonio no mundo.

Ao Antonio, meu amor, por ter participado mais que intimamente, aturando os ataques, as choradeiras, pelo incentivo, pelo amor, pelo companheirismo, pelas comemorações nas vitórias e por ser o cara mais maravilhoso que existe, muito obrigada lindão!!! Te amo mais que tudo nessa vida, você é pra sempre!!!

A Deus por ter me dado sorte de ter conhecido tanta gente bacana e por poder contribuir mesmo que minimamente para ciência!!!

"A verdadeira ciência descobre Deus à espera atrás de cada porta."

Papa Pio XII 


\section{SUMÁRIO}

Resumo - - 15

Abstract _ 17

1- Introdução e Justificativa-_- 19

2- Revisão da Literatura-_ 21

2.1- Rins e Doença Renal Crónica-___ 21

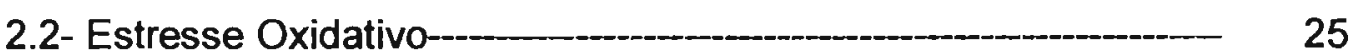

2.3- Peroxidação Lipidica-___ 26

2.4- Peroxidação Lipídica na Doença renal crônica-___ 32

2.5- Vitamina E e C como antioxidantes e Peroxidaçăo Lipídica na $\quad 35$ doença renal crônica-

3- Objetivo -._- 38

3.2- Objetivo geral-_- 38

3.3- Objetivos especificos-_ 38

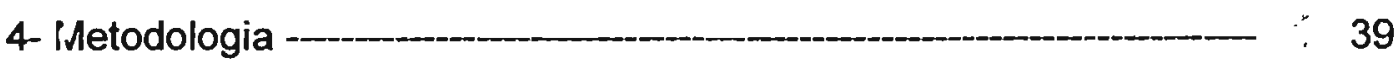

4.1- Casuística - 39

4.2- Procedimentos éticos - 39

4.3- Critérios de inclusão - $\quad 39$

4.4- Critérios de exclusão -..- 39

4.5- Dados demográficos, clínicos e bioquímicos --_- 40

4.6- Avaliação antropométrica -_-__ 40

4.7- Coleta de sangue-- 42

4.8- Separação da LDL eletronegativa-_- 43

4.9- Determinação da concentração de LDL eletronegativa---_-_--- $\quad 44$

5.0- Determinação de anticorpos anti-LDL eletronegativa --_-_-_- 45

5.1- Deteç̧ão de Imunocomplexos --_ 46

5.2- Determinação de Ascorbato e Alfa-tocoferol ---_- $\quad 47$

5.3- Análise estatística - -

6- Resultados - 49

6.1- Caracteristica dos grupos _ $\quad 49$

6.2- Dados amtropométricos dos participantes do estudo ---_-_- 50 
6.3- Perfil Lipidico -

6.4- LDL eletronegativa --_- 52

6.5- Auto-Anticorpos Anti-LDL (-) -

6.6- Imunocomplexos - 54

6.7- Ascorbato plasmático --_- 55

6.8- Alfa-Tocoferol plasmático - 56

6.9- Correlações - 56

7- Discussão - 60

8- Conclusão _ 66

9- Referência bibliográfica - 67

Anexos 


\section{Lista de llustrações}

\section{Tabelas}

Tabela 1: Características gerais dos grupos estudados-- 49

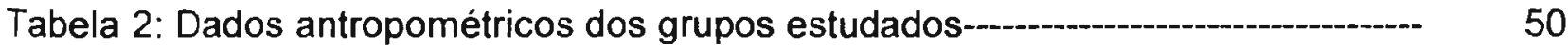

Tabela 3: Ferfil Lipidico dos grupos estudados-- 51

Tabela 4: Concentração de Tocoferol em umoles/mg de colesterol-_-________ 56

\section{Figuras}

Figura 1: Estrutura dos Rins---- 21

Figura 2: Estrutura do Néfron-1 22

Figura 3: Ilustração de um paciente em diálise peritoneal --_-_-_-_-_ 23

Figura 4: Ilustração de um paciente em hemodiálise -

Figura 5: Acesso vascular na hemodiálise (fístula arterio-venosa)-_____-_ 24

Figura 6: Estágios iniciais da formaçăo da lesăo aterosclerótica-_an 28

Figura 7: Heterogenicidade da LDL eletronegativa e participação na aterogênese 31

\section{Gráficos}

Gráfico 1: Porcentagem dos pacientes com baixas concentrações de HDL- 51 colesterol e concentrações elevadas de LDL-colesterol, colesterol total e triglicérides (TG).

Gráfico 2: Concentraçöes de LDL(-) $(\mu \mathrm{g} / \mathrm{mL})$ nos grupos estudados---_- 52

Gráfico 3:Concentraçס̋es de Anti-LDL(-) $\operatorname{lgG}$ Auto-anticorpo $(\mu \mathrm{g} / \mathrm{mL})$ nos grupos 53 estudados

Gráfico 4: Concentrações de Imunocomplexos $(\mu \mathrm{g} / \mathrm{mL})$ nos grupos estudados --.-- 54

Gráfico 5: Concentrações de Ascorbato plasmático ( $\mu \mathrm{M} / \mathrm{L})$ nos grupos estudados--- 55

Gráfico 6: Correlação entre Imunocomplexos lgG ( $\mu \mathrm{g} / \mathrm{mL})$ e PCT (mm)

Gráfico 7: Correlação entre LDL(-) $(\mu \mathrm{g} / \mathrm{mL})$ e PCT $(\mathrm{mm})$

Gráfico 8: Correlação entre Anticorpos Anti-LDL(-) $\mathrm{lgG}(\mu \mathrm{g} / \mathrm{mL})$ e IMC $\left(\mathrm{Kg} / \mathrm{m}^{2}\right)$-_-_- 58

Gráfico 9: Correlação entre Anticorpos Anti-LDL(-) $\operatorname{lgG}(\mu \mathrm{g} / \mathrm{mL})$ e circunferência da 58 cintura $(\mathrm{cm})$

Gráfico 10: Correlação entre LDL(-) $(\mu \mathrm{g} / \mathrm{mL})$ e Anticorpos Anti-LDL(-) $\mathrm{lgG}(\mu \mathrm{g} / \mathrm{mL})--$ 


\section{Quadros}

Quadro I: Divisão dos estágios da DRC de acordo com NKF, 200223

Quadro II: Estado Nutricional de Adultos segundo o IMC40

Quadro III: Estado Nutricional de Adultos segundo a AMBC 41

Quadro IV: Estado Nutricional de Adultos segundo o PCT 42 
Lista de abreviaturas e siglas

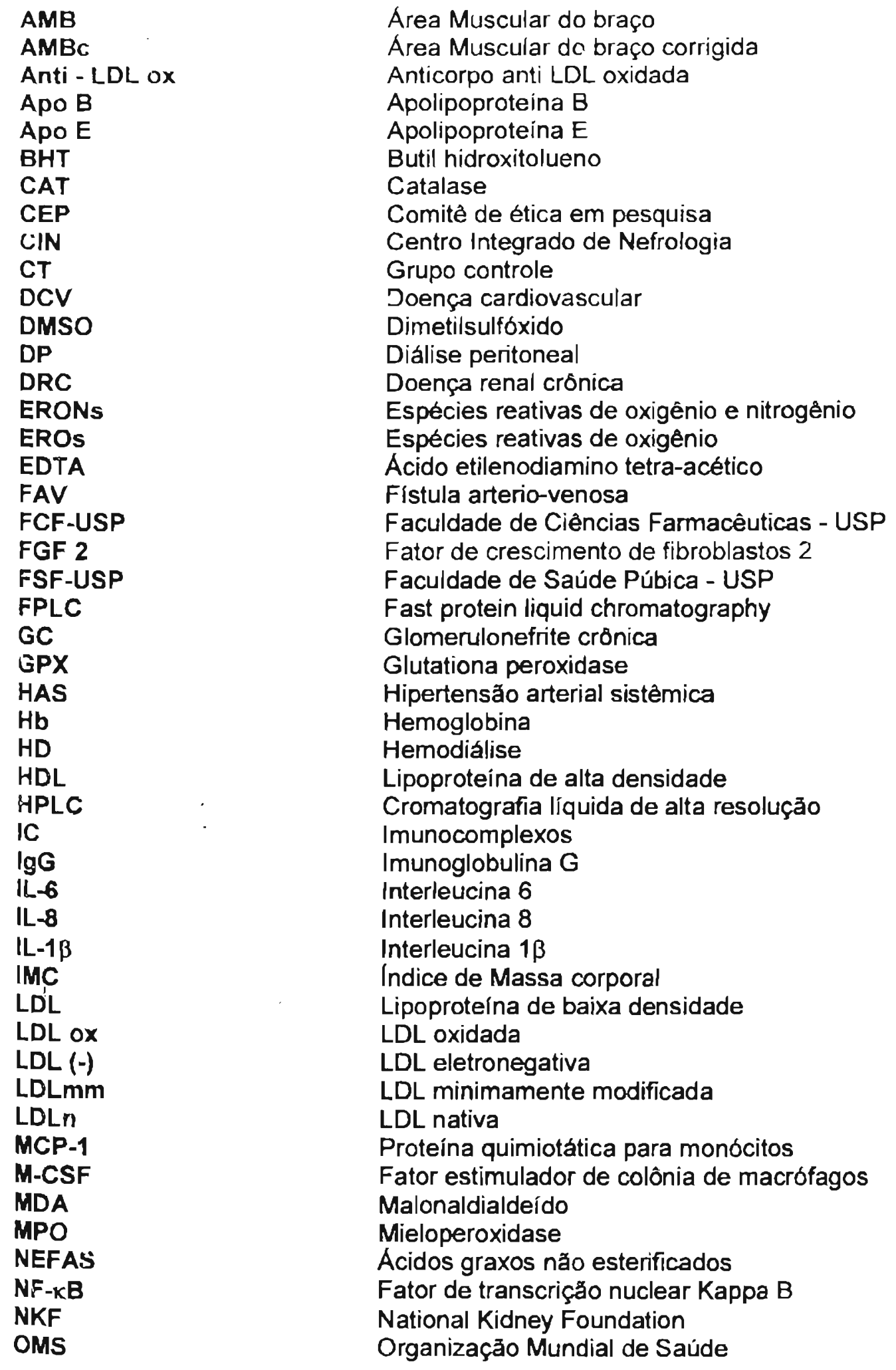




$\begin{array}{ll}\text { OPD } & \text { Fenilenodiamina } \\ \text { PAF-AH } & \text { Fator ativador de plaquetas acetil hidrolase } \\ \text { PBS } & \text { Tampão fosfato } \\ \text { PCR } & \text { Proteina C reativa } \\ \text { PCT } & \text { Prega cutânea tricipital } \\ \text { PLA-2 } & \text { Fosfolipase } \downarrow 2 \\ \text { PMSF } & \text { Fenilmetilsulfonilflorideo } \\ \text { PUFA } & \text { Acido graxo polinsaturado } \\ \text { RP } & \text { Rins Policísticos } \\ \text { SDS } & \text { Dodecil sulfato de sódio } \\ \text { SOD } & \text { Superóxido dismutase } \\ \text { TFG } & \text { Taxa de filtração glomerular } \\ \text { TG } & \text { Triglicerídeos } \\ \text { TNF- } \alpha & \text { Fator de necrose tumoral } \alpha \\ \text { VCAM-1 } & \text { Moléculas de adesão de células vasculares } \\ \text { VLA-4 } & \text { Integrina } \\ \text { VLDL } & \text { Lipoproteína de densidade muito baixa }\end{array}$




\section{RESUMO}

A modificação oxidativa da LDL possui um papel crucial na patogênese da aterosclerose que é uma das principais causas de mortalidade nos pacientes renais crônicos. Uma subfração de LDL modificada in vivo, denominada LDL eletronegativa (LDL-), é formada a partir de modificações da parte protéica (ApoB100) e lipídica (fosfolipides, triglicérides e colesterol) da LDL induzidas por diversos mecanismos. A LDL (-) tem menor afinidade pelos receptores da LDL, é citotóxica para células endoteliais e apresenta atividade pró-inflamatória, quando comparada à LDL nativa. Com o objetivo de investigar as alterações do estado nutricional relacionadas à formação da LDL(-) nos pacientes renlais crônicos, analisou-se neste estudo as concentrações plasmáticas de LDL(-), anticorpos lgG anti-LDL(-) e seus imunocomplexos em pacientes sob hemodiálise (HD, $n=25)$ ou sob diálise peritoneal (DP, $n=11$ ) e indivíduos saudáveis (grupo controle, $n=10$ ), relacionando-as ao perfil lipidico e às concentrações plasmáticas de $\alpha$-tocoferol e ascorbato. Ọs resultados mostraram que a concentração de $L D L(-)$ foi maior $(p<0.01)$ nos pacientes hemodialisados $(575,6 \pm 233,1 \mu \mathrm{g} / \mathrm{mL})$ quando comparados aos pacientes submetidos à diálise peritoneal $(223,4 \pm 117,5 \mu \mathrm{g} / \mathrm{mL})$ e aos controles $(54,9 \pm 33,3 \mu \mathrm{g} / \mathrm{mL})$. Os níveis de anticorpos IgG anti-LDL(-) foram mais elevados $(p<0,00001)$ nos controles $(0,36 \pm 0,09 \mu \mathrm{g} / \mathrm{mL})$, quando comparados aos pacientes DP $(0,28 \pm 0,12 \mu \mathrm{g} / \mathrm{mL})$ e HD $(0,2 \pm 0,1 \mu \mathrm{g} / \mathrm{mL})$. As concentrações dos imunocomplexos no grupo controle $(0,35 \pm 0,20 \mu \mathrm{g} / \mathrm{mL})$ foram significativamente maiores comparadas às dos grupos HD $(0,15 \pm 0,07 \mu \mathrm{g} / \mathrm{mL})$ e DP $(0,22 \pm 0,07 \mu \mathrm{g} / \mathrm{mL})$. Não houve diferença das concentrações plasmáticas de ascorbato e de alfa-tocoferol (normalizada pela conceritração de colesterol) nos grupos estudados. A maioria da população estudada estava eutiófica, segundo o indice de massa corpórea (IMG). Conclui-se que as concentracöes de 1.DL. - ) nos pacientes HD e DP foram significativamente mais elevadas, enquanto os níveis de anticorpus lgG anti-LDL(-) foram menores, nos pacientes HD e DP comparados ao grupo controle. As análises de correlação demonstraram que os valores de prega cutânea tricipital (PCT) se correlacionaram diretamente com as concentrações plasmáticas dos imunocomlexos $(r=0,37 ; p=0,01)$ e inversamente com as 
concentrações plasmáticas de $\operatorname{LDL}(-)(r=-0.37 ; p=0,018)$. As concentrações plasmáticas dos anticorpos anti-LDL(-) se correlacionaram diretamente com os valores do IMC $(r=0,83 p=0,00001)$ e da circunferência da cintura $(r=0,75 p=0,0001)$.

Palavras chave: Hemodiálise, Diálise peritoneal, LDL eletronegativa, Doença Cardiovascular. 


\section{ABSTRACT}

A minimally modified form of LDL, with structural ApoB100 modification and lower affinity by LDL receptors, has been described in blood plasma. This circulating modified form of LDL, named electronegative LDL, LDL(-), has increased negative charge, higher cytotoxicity and pro-inflammatory activity as compared to the native LDL. This LDL-is poorly described in hemodialysis and there is no study in peritoneal dialysis patients. Thus, the purpose of this study was to evaluate the relation of the nutritional status with the amount of electronegative LDL (LDL-), its autoantibodies and immune complexes (IC) in dialysed patients. LDL(-), its autoantibodies and IC were determined by ELISA in chronic kidney disease (CKD) patients undergoing hemodialysis (HD) or peritoneal dialysis (PD) and compared to subjects without CKD (controls). Nutritional status, lipid profile and plasma concentrations of alpha-tocopherol, ascorbate and immune complexes (IC) were also evaluated. Results are expressed as median of $L D L-(\mu \mathrm{g} / \mathrm{mL}$. $)$ and anti-LDL(-) IgG (OD405 nm). The concentrations of LDL(-) were higher in HD patients $(575.6 \pm 233.1 \mu \mathrm{g} / \mathrm{mL})$ as compared to $P D(223.4 \pm 117.5 \mu \mathrm{g} / \mathrm{mL})$ and control groups $(54.9 \pm 33.3 \mu \mathrm{g} / \mathrm{mL})(p<0.01)$. The anti-LDL(-) IgG auto-antibodies were elevated in controls $(0.36 \pm 0.09 \mu \mathrm{g} / \mathrm{mL})$ in relation to $P D$ patients $(0.28 \pm 0.12 \mu \mathrm{g} / \mathrm{mL})$ and $H D$ patients $(0.2 \pm 0.1 \mu \mathrm{g} / \mathrm{mL}), \quad(p<0.00001)$. A negative correlation was observed between anti$\operatorname{LDL}(-) \lg G$ and $\operatorname{LDL}(-)$ levels $(r=-0.43 ; p=0.003)$ in the studied groups. The concentrations of IC in the control group $(0.35 \pm 0.20 \mu \mathrm{g} / \mathrm{mL})$ were higher compared with $\mathrm{HD}(0.15 \pm 0.07 \mu \mathrm{g} / \mathrm{mL})$ and $P D(0.22 \pm 0.07 \mu \mathrm{g} / \mathrm{mL})$ groups. No differences were found for the plasma levels of ascorbate and alpha-tocopherol (normalized by cholest.rol concentration) among the studied groups The body mass index (BMI) was normal in the majority of the studied subjects. The highest LDL(-) concentrations were found in HD patients, and for the first time, we showed that PD patients also have high levels of LDL(-) when compared with non-CKD subjects. The levels of anti-LDL(-) IgG in CKD patients were lower compared to controls. The correlation analysis showed that the values for triceps skin fold were positively correlated with blood plasma concentrations of IC $(r=0.37 ; p=0.01)$ and negatively correlated with LDL(-) concentrations $(r=-0.37 ; p$ $0.018)$. The concentrations of anti-LDL(-) autoantibodies were directly correlated with 
$\mathrm{BMI}(r=0.83 p=0.00001)$ and waist circunference $(r=0.75 p=0.0001)$.

Key Words: Hemodialysis, peritoneal dialysis, electronegative LDL, cardiova ;cular disease. 


\section{INTRODUÇÃO E JUSTIFICATIVA:}

A principal causa de morte em pacientes portadores de doença renal crônica (DRC) é a doença cardiovascular ( $\mathrm{DCV}$ ) e pesquisas têm mostrado que além de todos os fatores já estabelecidos, o estresse oxidativo parece ter um papel importante no desenvolvimento de $\mathrm{DCV}$, principalmente nos pacientes que estão sob hemodiálise (Prichards, 2003). O estresse oxidativo, pode ser definido como dano tissular decorrente de um desequilibrio entre a geração excessiva de compostos oxidantes ou espécies reativas de oxigênio e nitrogênio (ERONs) e a deficiencia dos sistemas de defesa antioxidante (Locatelli et al., 200.3).

Uma das conseqüências do aumento das ERONs é a oxidação das partículas de LDL, originando partículas de LDL oxidada (LDL-ox) com propriedades citotóxica, próinflamatória e pró-aterogênica (Molavi \& Mehta, 2004). Evidências indicam que a modificação oxidativa da LDL induz o acúmulo de lipidios na parede arterial (Radulesco et al. 2004). A partícula LDLox é considerada um importante fator na iniciação e propagação da placa aterosclerótica (Asatryan et al. 2003; Molavi \& Mehta, 2004). Além da LDLox, que está presente na parede do vaso, uma forma modificada de LDL, chamada LDL eletronegativa(LDL-) está presente na circulação sanguinea.

A relação entre $L D L(-)$ e aterosclerose, revela uma variedade de atividades biológicas, incluindo citotoxicidade em células endoteliais e efeitos pró-inflamatórios (Hodis et al., 1994; Sevanian et al., 1995 e1997; Chang et al., 1997). Alg Ins estudus mostram aumento da concentração sérica da LDL(-) em pacienies com alto risco cardiovascular, hipercolesterolemia familiar, hipertrigliceridemia e diabetes mellitus (Gomes et al., 2004; Oliveira et al., 2006 ; Tai et al., 2006; Bernitez et al., 2006)

Existe um único estudo descrito sobre as alteraçōes da LDL(-) em pacie: ttes renais crônicos hemodialisados (Ziouzenkova et al. 1999), mas náo há nenhum es "udo em pacientes sob diálise peritoneal. Estudos sobre o aumento da peroxidação lipidica nestes pacientes são de extrema importância, visto que a deteç̧ão precoce destas alterações poderá contribuir para reduzir as complicações das DCV, o que refletiria na qualidade de vida nos pacientes renais crônicos (Kohlhagen \& Kelly, 2003; Snively \& Gutierrez, 2004). Neste estudo nos propomos avaliar as concentrações de LDL(-), seus 
auto-anticorpos e imunocomplexos (IC) em pacientes renais crônicos sob hemodiálise e diálise peritoneal e relacioná-las ao estado nutricional destes pacientes. 


\section{REVISÃO DA LITERATURA:}

\subsection{Rins e Doença Renal Crônica}

Os rins são órgãos que lembram a forma de um grão de feijão, de coloração marrom-avermelhada, situados no espaço retroperitoneal, um de cada lado da coluna vertebral (Riella et al., 2003 ).

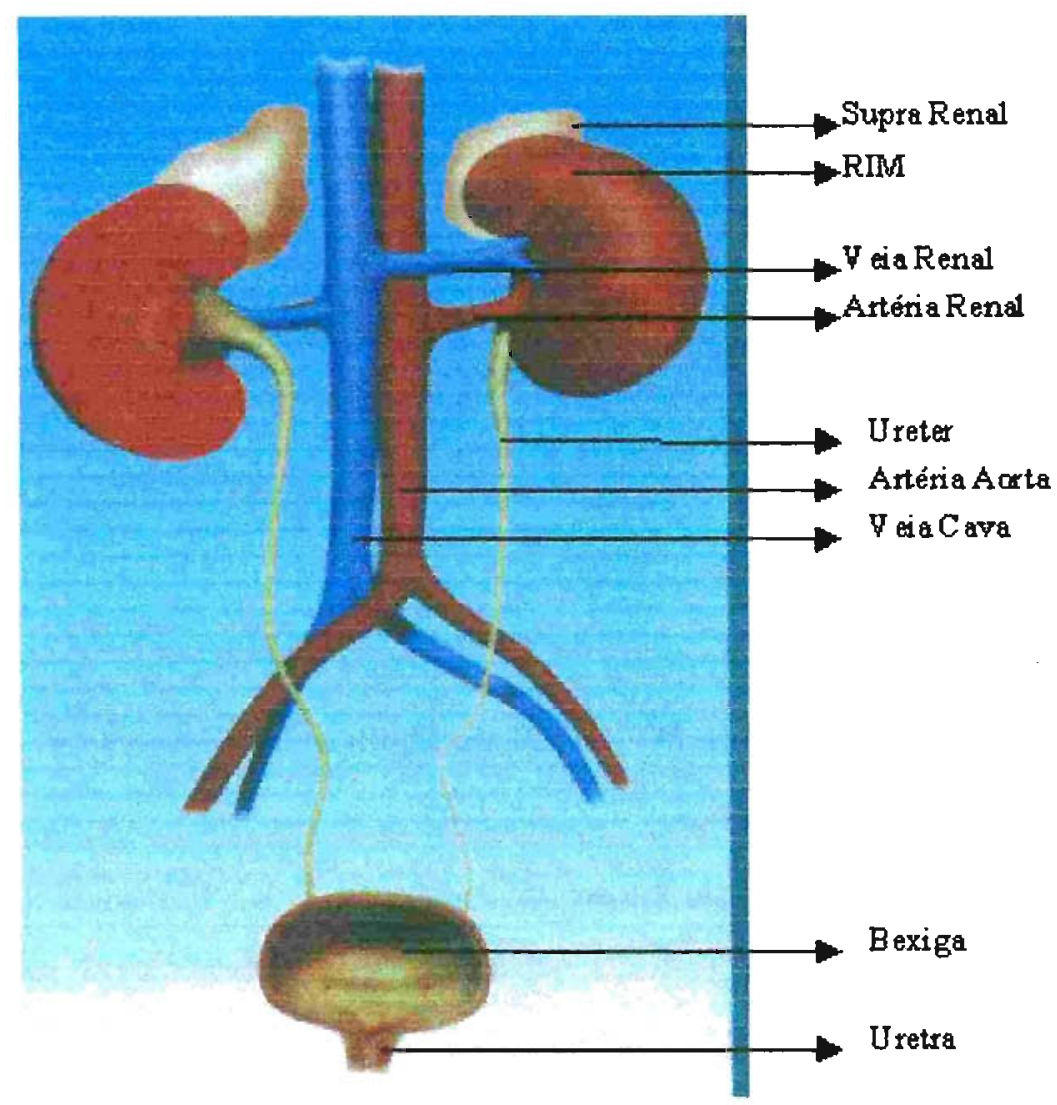

Figura 1: Estrutura dos Rins (Sociedade Brasileira de Nefrologia- SBN, 2004)

Os rins são considerados órgãos reguladores que, seletivamente excretam e conservam água e vários compostos químicos. Desta forma, ajudam a preservar a constância do meio interno, onde: mantêm o volume líquido, a osmolaridade, as concentraçōes de eletrólitos, e do estado ácido-básico; promovem excreção de produtos finais do metabolismo como, uréia, ácido úrico, fosfatos e sulfatos, bem como drogas e medicamentos. Além disto, os rins regulam a pressão arterial, produzem eritropoetina e promovem a ativação da vitamina $\mathrm{D}$, essencial na regulação do balanço de cálcio e fósforo. 
Os rins ainda catabolizam proteínas de baixo peso molecular, sendo responsáveis por várias funções metabólicas como, por exemplo: amoniogênese e gliconeogênese (Valtin \& Schafer, 1995).

O néfron é a unidade funcional dos rins, e é nesta estrutrura onde ocorrem todas as funções renais. Os rins contêm aproximadamente dois milhōes de néfrons (Figura 2).

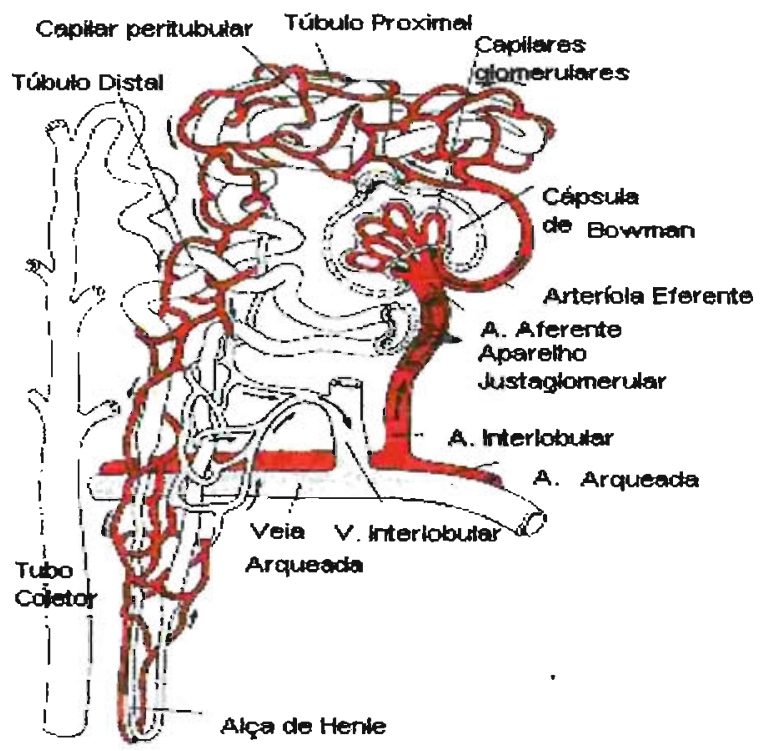

Figura 2: Estrutura do Néfron (Marieb, 1991).

A perda lenta, progressiva e irreversível dessas funções renais caracteriza a Doença Renal Crônica (DRC). Segundo a literatura, esta doença resulta em significante morbimortalidade, pois devido à importância da função dos rins na manutenção da homeostasia, a DRC pode afetar quase todos os sistemas do organismo (Snively \& Gutierrez, 2004).

Segundo o National Kidney Foundation (1998), (Quadro I) a progressão da doença foi dividida em 5 estágios de acordo com a taxa de filtração glomerular (TFG), sendo que os quatro primeiros correspondem à fase pré-dialítica (tratamento conservador), marcada pela síndrome urêmica, com progressivas alterações da homeostasia do organismo. Quando este tratamento não é mais suficiente, a terapia renal substitutiva deve ser introduzida, como, hemodiálise ou diálise peritoneal (Baiardi, 2002). 
Quadro I: Divisão dos Estágios da DRC de acordo com o NKF, 2002.

\begin{tabular}{|lll|}
\hline Estágios & Descrição & TFG $^{*}\left(\mathrm{~mL} / \mathrm{min}^{\left.1,73 \mathrm{~m}^{2}\right)}\right.$ \\
\hline 1 & Lesão renal - TFG normal ou $\uparrow$ & $\geq 90$ \\
2 & Lesão renal - discreto $\downarrow$ TFG & $60-89$ \\
3 & Moderada $\downarrow$ TFG & $30-59$ \\
4 & Severa $\downarrow$ TFG & $15-29$ \\
5 & Insuficiência renal & $<15$ \\
\hline
\end{tabular}

Fonte: NKF, 2002

A diálise peritoneal (DP), utiliza a membrana peritoneal como um filtro, onde mantém o equilibrio metabólico através de uma solução eletrolitica de glicose (solução de diálise) na cavidade abdominal do paciente. Utiliza-se um cateter (rígido ou flexível) para acesso à cavidade, que envia a solução de diálise. As substâncias tóxicas e o excesso de água passam do peritôneo para a solução de diálise. Depois de algumas horas a solução é drenada do abdômem e repete-se todo o processo novamente (Gloor, 2003).

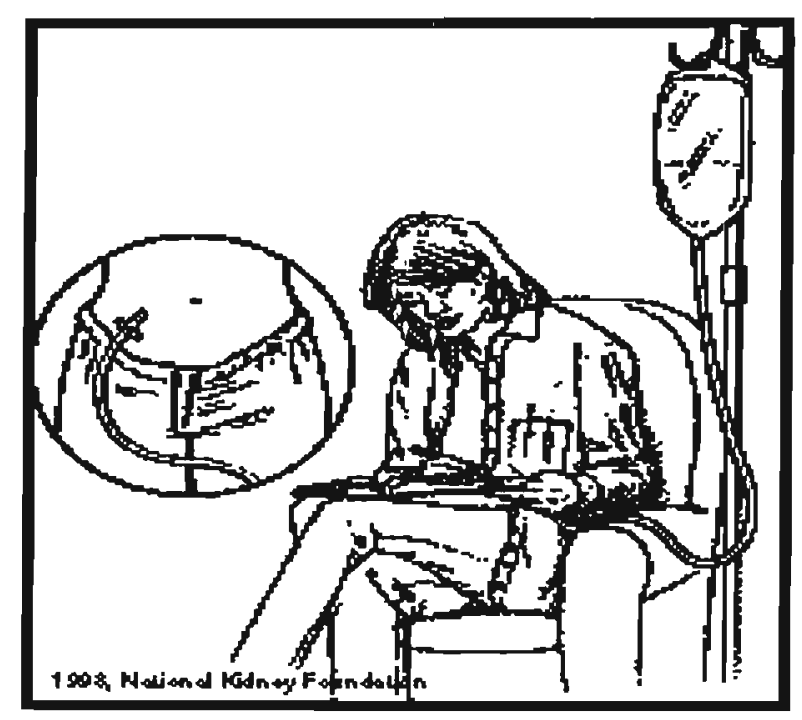

Figura 3: llustração de um paciente em diálise peritoneal. Fonte NKF, 1998 
A hemodiálise (HD) é um processo de filtração do sangue realizado por uma máquina, para remover o excesso de líquidos e metabólitos acumulados no organismo. Antes de iniciar o programa de HD, é necessário o acesso à circulação sangüinea do paciente. Esse acesso é a via através da qual o sangue é removido, enviando para dentro do hemodialisador, depurado e, então, retornado ao paciente. Existem diferentes tipos acesso, e todos requerem uma pequena cirurgia. Uma fístula arterio-venosa (FAV) é uma ligaçăo interna de uma artéria com uma veia (Riella \& Martins, 2003).

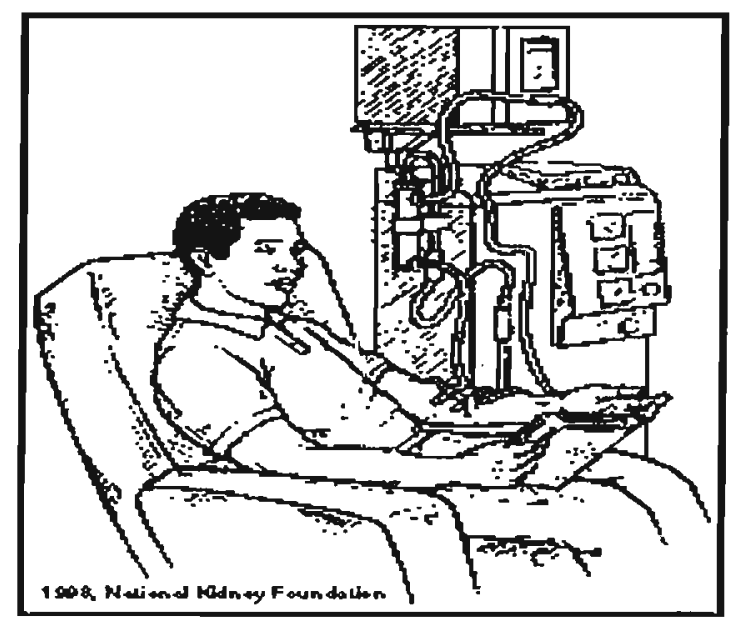

Figura 4: llustração de um paciente na hemodiálise. Fonte NKF,1998

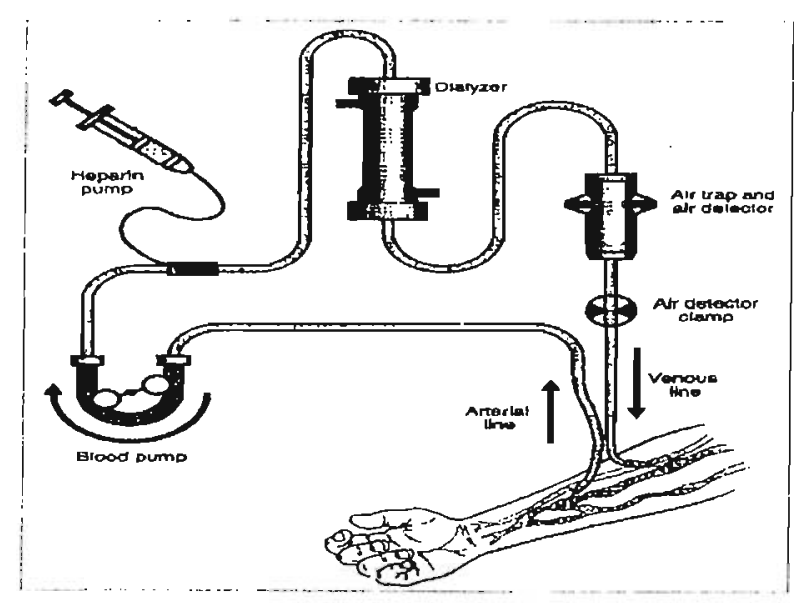

Figura 5: Acesso vascular na hemodiálise (fistula arterio-venosa). Fonte: NKF, 1998 
Essas terapias substitutivas são fundamentais para prolongar a vida do pacieıte, no entanto, podem produzir reações inflamatórias e estresse oxidativo, devido ao ccintato do sangue com a superficie do dialisador, resultando no acúmulo de proteínas modificadas e produtos da peroxidação lipidica, aumentando a formação de LDL oxidada, o que poderia favorecer o desenvolvimento da aterosclerose (Fields 1999; Ziouzenkova et al., 2002; Van et al., 2003; Kalantar-Zadeh et al., 2005). Assim, o estressa oxidativo parece ter um papel importante no desenvolvimento de DCV, que é uma causa importante de mortalidade nos pacientes renais crônicos (Prichards, 2003).

\subsection{Estresse oxidativo}

O estresse oxidativo pode ser definido como dano tissular decorrente de um desequilibrio decorrente da geração excessiva de espécies reativas de oxigênio (EROs) ou deficiência dos mecanismos de defesa antioxidante (Cadenas \& Sies, 1985; Locatelli et al., 2003). As EROs podem ser produzidas em diversas vias metabólicas, tais como, cadeia respiratória mitocondrial, $\mathrm{NAD}(\mathrm{P}) \mathrm{H}$ oxidase, xantina oxidase, lipoxigenase, cicloxigenase, heme oxigenase, enzimas do citocromo P-450, óxido nitrico sintase, dentre outras enzimas (Vaziri, 2004; Valko et al., 2006).

Em condições normais, existe um equilibrio entre a produção de EROs e os sistemas antioxidantes compostos por enzimas e antioxidantes da dieta. Na redução unieletrônica do oxigênio, a primeira ERO produzida é ânion-radical superóxido $\left(\mathrm{O}_{2}{ }^{\circ}\right)$, que é gerado a partir da redução do oxigênio molecular por um elétron.

$$
\left(\mathrm{O}_{2}+\mathrm{e} \rightarrow \mathrm{O}_{2}^{--}\right)
$$

Que é posteriormente convertido a peróxido de hidrogênio $\left(\mathrm{H}_{2} \mathrm{O}_{2}\right)$ por dismutação direta ou catalisada pela enzima superóxido dismutase (SOD).

$$
\left(2 \mathrm{O}_{2}{ }^{--}+2 \mathrm{H}^{+}+\mathrm{SOD} \rightarrow \mathrm{H}_{2} \mathrm{O}_{2}+\mathrm{O}_{2}\right)
$$

O peróxido de hidrogênio é reduzido à água pela catalase (CAT).

$$
\left(2 \mathrm{H}_{2} \mathrm{O}_{2}+\mathrm{CAT} \rightarrow 2 \mathrm{H}_{2} \mathrm{O}+\mathrm{O}_{2}\right)
$$

Ou glutationa peroxidase (GPX), que utiliza glutationa como doador de hidrogênio.

$$
\left(\mathrm{H}_{2} \mathrm{O}_{2}+2 \mathrm{GSH} \rightarrow 2 \mathrm{H}_{2} \mathrm{O}+\mathrm{GS}-\mathrm{SG}\right) \text {. }
$$


Fisiologicamente, as EROs são convertidas a água e oxigênio molecular, mas em prısença de metais de transição (ferro ou cobre) ou excesso de $\mathrm{O}_{2}{ }^{\circ}, \mathrm{o}_{2} \mathrm{O}_{2}$ é convertido a radical hidroxila $(\mathrm{OH})$, que é altamente reativo e causa lesర̃es oxidativas em lípides, proteínas, açúcares e ácidos nucléicos. Este radical livre pode iniciar a peroxidação lipídica na presença de ínns de metais de transição, tais como ferro e cobre (.Descamps-Latscha.: 2001; Drüeke et al., 2001; Vaziri, 2004; Valko et al., 2006).

$$
\begin{gathered}
\mathrm{H}_{2} \mathrm{O}_{2}+\mathrm{Fe}^{2} \rightarrow . \mathrm{OH}+\mathrm{OH}^{-}+\mathrm{Fe}^{3} \\
\text { (reação de Fenton) } \\
\mathrm{H}_{2} \mathrm{O}_{2}+\mathrm{O}_{2}^{--} \rightarrow . \mathrm{OH}+\mathrm{OH}^{-}+\mathrm{O}_{2} \\
\text { (Reação de Haber-Weiss) }
\end{gathered}
$$

A mieloperoxidase (MPO) utiliza peróxido de hidrogênio $\left(\mathrm{H}_{2} \mathrm{O}_{2}\right)$ para a geração do ácido hipocloroso (HOCL), que é também altamente reativo. O HOCL pode interagir com várias moléculas, especialmente proteínas. Outra reação importante é a interação

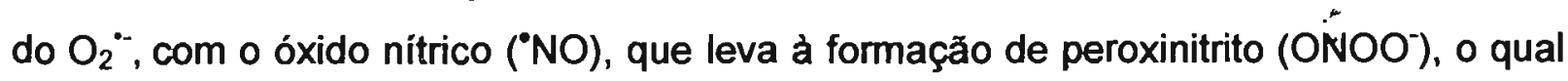
pode causar danos no DNA, nitração de proteínas e peroxidação lipídica (Vaziri, 2004).

\subsection{Peroxidação Lipídica}

Uma das principais conseqüências do aumento das EROs é a oxidação das partículas de LDL, formando LDL oxidada (LDL-ox), que possui alta bioatividade (Molavi \& Mehta, 2004). EROs geradas por células inflamatórias ou derivadas de peroxidases têm sido propostas como agentes responsáveis pela oxidação da LDL na parede arterial. A peroxidação lipídica é iniciada pelo ataque de radicais livres às duplas ligações de ácidos graxos poliinsaturados (PUFA), onde ocorre a remoção do átomo de hidrogênio do grupo metila do PUFA e a formação de um dieno conjugado com uma configuração mais estável. Esse dieno conjugado reage rapidamente com oxigênio molecı.lar, formando o radical peroxila, o qual remove um átomo de hidrogênio de um PUFA adjacente para formar hidroperóxido e outro radical lipídico, havendo a propagação da cadeia radicalar da lipoperoxidação. Desta forma, ocorre a produção de oxiesteróis, hidroperóxidos lipídicos e aldeídos, incluindo o malonaldialdeído (MDA) 
(Sniderman, 2004). Esses aldeídos reativos podem se ligar ao grupo amino da apoB100 na LDL, aumentando a carga negativa. O receptor de LDL em situações normais, reconhece um domínio especifico na ApoB100, contendo cargas positivas da lisina, arginina e histidina; no entanto, alterações neste domínio resulta na diminuição da ligaŗão da ApoB com o receptor. Um aumento da carga negativa da ApoB100, resultante da formação de lisolecitina e da derivatização de resíduos lisina, faz com que ocorra menor afinidade da $L D L$ por seus receptores $B / E$ e maior reconhecimento da LDL por receptores scavenger, presentes em macrófagos, o que induz a formação das foam cells (células espumosas) no processo inicial da aterogênese (Young \& McEneny, 2001; Sniderman, 2004). Portanto, o acủmulo de lipidios na parede arterial depende da modificação oxidativa da LDL (Radulesco et al. 2004). A partícula de LDLox é considerada um importante fator na iniciação e propagação da placa aterosclerótica, processos inflamatórios e acúmulo de lipídios na parede arterial (Asatryan et al. 2003; Molavi \& Mehta, 2004).

No início do processo aterosclerótico, a LDL oxidada estimula as céli as endoteliais a produzirem numerosas moléculas pró-inflamatórias, incluindo moléci:las de adesão e fatores de crescimento. O rolamento dos leucócitos através da superficie endotelial é mediado por selectinas; a adesão de monócitos e células $T$ ao endotélio, é mediac a pela integrina VLA-4 presente nestas células, que interagem com VCAM-1. A citociná M-CSF (fator estimulador de colônia de macrófagos) estimula a proliferação e diferenciação de macrófagos e influencia suas funçōes como por exemplo, a expressão de receptores scavenger. O reconhecimento das partículas de LDLox pelos receptores scavenger induz a formaŗão das células espumosas (foam cells). Na evolução das lesōes ocorre a formação da placa fibrosa, formada em decorrência da proliferação e acúmulo de células musculares lisas. Na lesōes caracterizadas por uma fina cápsula fibrosa e aumento de células inflamatórias pode ocorrer o rompimento da placa aterosclerótica e o desenvolvimento da trombose. A estabilidade da lesão aterosclerótica pode ser influenciada pela calcificação ou neovascularização, fatores comuns em lesões avançadas. As lesões podem reduzir o lúmem arterial, diminuindo o fluxo sanguíneo, o que causa manifestaçōes clínicas tais como e o angina pectoris e infarto agudo do miocárdio. Este processo ocorre de forma progressiva e gradual ao 
longo da vida (Lusis, 2000; Libby, 2002). Na figura 3 pode ser visto o processo inicial da formação das placas ateroscleróticas.

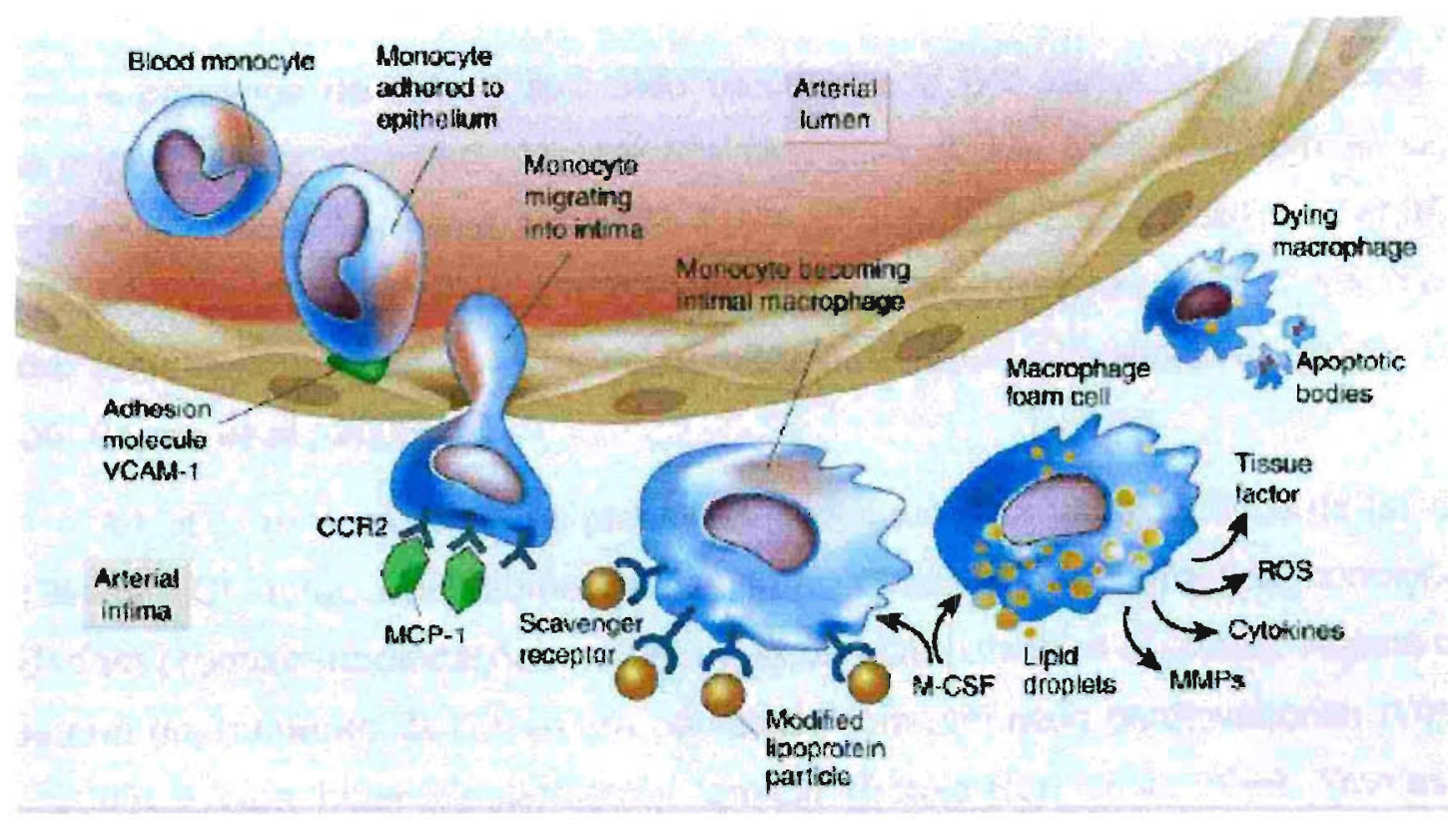

Fonte: Libby, 2002

Figura 6: Estágios iniciais da formação da lesão aterosclerótica.

Como já citado acima, os aldeídos reativos podem aumentar a carga negativa da LDL e isso foi visto pela primeira vez em 1988 por Avogaro et al., que isolaram por cromatografia de troca aniônica, uma fração da LDL com maior carga negativa do plasma de individuos normolipidêmicos, denominando-a de LDL eletronegativa, [LDL()], a qual apresentava características semelhantes à LDL minimamente oxidada.

O pool de partículas de LDL(-) não é formado exclusivamente pela oxidação da LDL, mas também origina-se de outros processos, como a glicação não enzimática, o enriquecimento em ácidos graxos não esterificados (NEFAs), modificações enzimáticas por fosfolipases, reação cruzada com a hemoglobina e outros mecanismos ainda não identificados ((Ursini \& Sevanian 2002; Sanchez-Quesada et al., 2004). A subfração de LDL(-) constitui-se em um pool de partículas heterogêneas em tamanho, com tendência à agregação, conteúdo diminuído de fosfolipídios e vitamina $\mathrm{E}$, e aumento de colesterol 
livre e proteinas, quando comparada à LDL nativa (LDLn) (Avogaro et al., 1988). Diferente da LDL oxidada in vitro, a LDL(-) não apresenta fragmentação da ApoB100 e outras alterações decorrentes de uma oxidação excessiva. Esta observação deu origem ao termo "LDL minimamente modificada" (LDLmm), empregado por alguns gr spos ao se referirem à LDL de Avogaro (Berliner et al., 1990).

A presença da LDL(-) tem sido demonstrada por vários pesquisadores, porém sua origem ainda não está esclarer:ida (Avogaro et al., 1988; Demuth et al., 1996; Vedie et al., 1998; Tertov et al., 1998; Moro et al., 1999; De Castellarnau et al., 21:00; Rigla et al., 2000; Chen et al., 2003; Pereira et al., 2004; Gomes et al., 2004; Yao et ai., 2004; Sanchez-Quesada et al. 2005; Bernitez et al. 2006, Oliveira et al., 2006; Tai el al. 2006; Barros et al., 2006).

4 LDL(-) está presente no plasma de indivíduos normolipidémicos na faixa de 0,1 a 5\% da LDL total, mas aumenta consideravelmente em diferentes condiçōes que poderiam produzir modificações na estrutura da LDL (Ursini et al.,2002). Alguns estudos mostram um aumento da LDL(-) em pacientes com alto risco cardiovascular (Oliveira et al., 2006) e com hipercolesterolemia familiar (Bittolo-Bon et al. 1986; Gomes et al., 2004), hipertrigliceridemia (Vedie et al. 1998; Sanchez-Quesada et al., 2002; Tai et al., 2006), diabetes mellitus tipos 1 e 2 [Sanchez-Quesada et al., 2001; Moro et al., 1999; Yano et al., 2004; Sanchez-Quesada et al., 2005; Bernitez et al., 2006; Gambino et al., 2006, Apolinário et al, 2006), e atletas com atividade aeróbica intensa (Bernitez et al., 2002). A LDL eletronegativa é citotóxica para células endotelias, induzindo a apoptose e a produção de citocinas (IL-8), proteínas quimiotáticas para monócitos (MCP-1), e moléculas de adesão de células vasculares (VCAM-1) (Bernítez et al. 2004).

A relaçāo entre a $\operatorname{LDL}(-)$ e a aterosclerose revela uma variedade de atividades biológicas, incluindo citotoxicidade e recrutamento de leucócitos.(Hodis et al., 1994; Sevanian et al., 1995 e1997; Chang et al., 1997). Chen et al. (2003), demonstraram que em pacientes com hipercolesterolemia familiar, a LDL eletronegativa induzia apoptose de células endoteliais vasculares pela inibição da transcriçăo do fator de crescimento de fibroblastos 2 (FGF-2). A LDL(-) isolada de pacientes normolipidêmicos (de Castellarnau et al., 2000; Sanchez-Quesada et al. 2003) e hipercolesterolêmicos (Benltez et al., 
2004) induz a expressão de IL-8 e da proteína quimiotática de monócitos 1(MCP-1), citocinas responsáveis pelo recrutamento de linfócitos e monócitos respectivamente na fase inicial da aterosclerose. Yang et al.(2003) observaram que a LDL(-), isolada de pacientes com hipercolesterolemia familiar, estimulava a adesão de células mononucleares em culturas de células endoteliais, o que poderia estar relacionado à expressão de IL-8, MCP-1 e VCAM-1 pela presença da LDL(-). A LDL(-) também aumenta a expressão do fator de necrose tumoral $\alpha$ (TNF- $\alpha$ ), induzindo a expressão de VCAM 1 através da ațvação do fator de transcrição nuclear Kappa B (NF-kB) (Ziouzenkova et al.,2003).

Adicionalmente, muitas evidências sugerem o papel de lipídios polares não oxidados (ácidos graxos não esterificados-NEFA e lisofosfatidilcolina), na indução da expressão de citocinas pela LDL(-). Suriyaphol et al. (2002) observaram que a LDL, modificada enzimaticamente pela colesterol esterase e tripsina, aumentava o conteúdo de NEFAs e induzia a produção de IL-8 por células endoteliais. Sonoki et al. (2003) relataram que PLA2 (fosfolipase A2) ligada à LDL modificada induzia a expressão de MCP-1, o que poderia estar relacionado à lisolecitina ou aos ácidos graxos insaturados, oxidados ou não, que poderiam atuar como indutores de respostas inflamatórias no endotélio. A associação entre a enzima PAF-AH (acetil hidrolase do fator ativador de plaquetas) e a LDL(-) também poderia contribuir para a liberação de citocinas (Bernite:. et al., 2003), uma vez que a hidrólise mediada pela PAF-AH gera lisofosfatidilcolina e NEFAS oxidados, que são mediadores inflamatórios (Stafforini et al., 1997; Nacphee et al., 1999; Tsimihodimos et al., 2002).

Estes estudos mostram que apesar de sua heterogenicidade quanto à origem, a LD'_(-) apresenta características inflamatórias e citotóxicas para células endoteliais, sugerindo seu envolvimento na ateroçênese (Sanchez-Quesada et. al., 2004), confor ne indicado na figura 7 . 


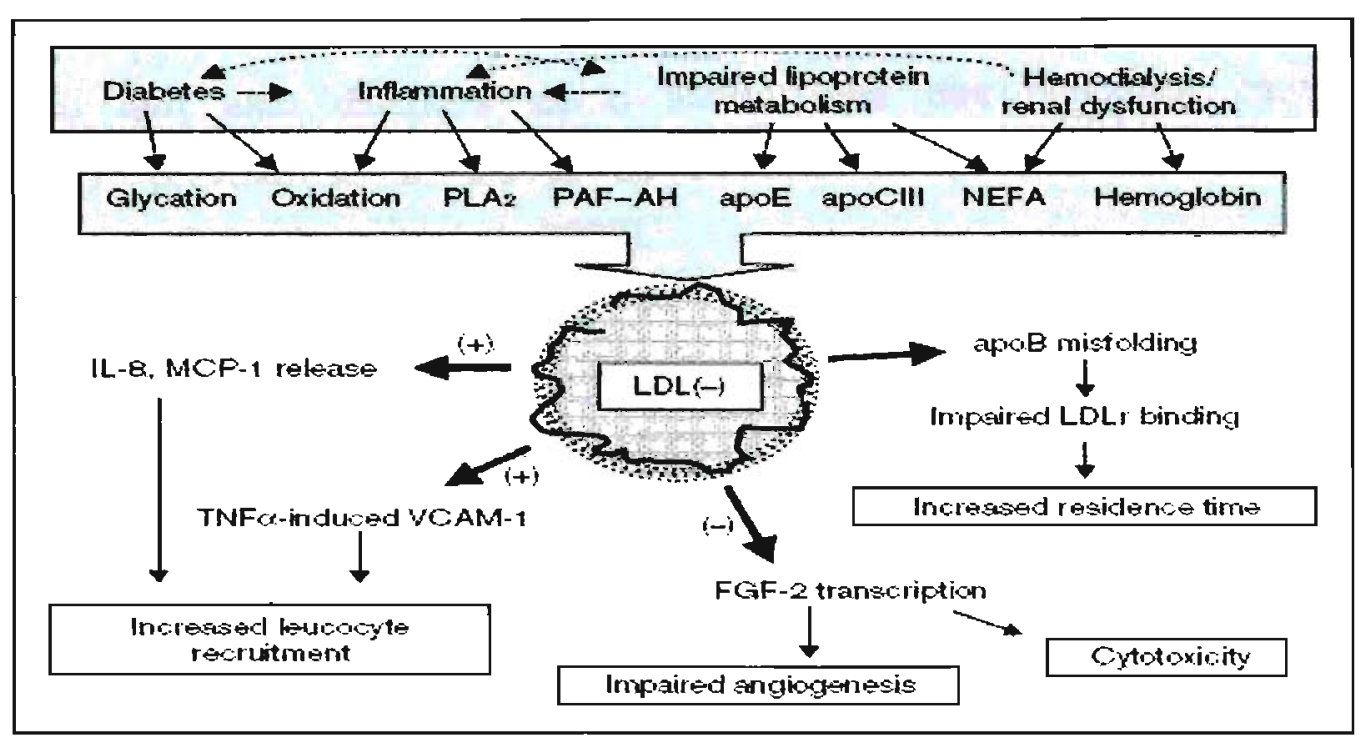

Fonte: Sánchez-Quesada et al., 2004

Figura 7: Heterogenicidade da LDL eletronegativa e participação na aterogênese.

Anticorpos que reconhecem as particulas de LDL modificadas também têm sido considerados como marcadores de risco da aterosclerose (Bergesio, 2001).

A presença da LDL minimamente modificada no plasma gera uma resposta autoimune com a formação de anticorpos e a subseqüentemente formação de imnunocomplexos (IC), que podem refletir a atividade da doença por um lado, mas também podem conferir proteção arterial. De acordo com Becarevic et al., (2005), esses anticorpos estão envolvidos no desenvolvimento da aterosclerose em modelos animais.

O papel dos anticorpos e sua relação com a progressăo da aterosclerose em humanos ainda não está claramente estabelecida (Bing et al., 2004). Mironova et al., (1997) demonstraram que a incubação de macrófagos humanos com LDL-IC induziu a formação de células espumosas. O papel pró-aterogênico dos LDL-IC in vivo também foi proposto, demonstrando-se níveis plasmáticos aumentados de LDL-IC em pacientes com doença coronariana (Tertov et al., 1996). 


\subsection{Peroxidação Lipídica na Doença Renal Crônica}

$\mathrm{Na}$ doença renal crônica (DRC), a patologia cardiovascular é complexa e a aterosclerose tem sido discutida como sendo uma das principais causas de mortalidade. A prevalência de placas de ateroma em pacientes urêmicos é de aproximadamente 30\% (Amann et al., 2003).

O estresse oxidativo possui numerosos fatores de relevância para aterogênese, mas os mecanismos envolvidos no desenvolvimento do estresse oxidativo nos doentes renais crônicos ainda não estão completamente elucidados (Ece et al., 2006). O paciente renal apresenta um processo inflamatório crônico, sendo este vinculado também ao estresse oxidativo que ativa o NF- $\mathrm{kB}$, que induz a sintese e liberação de citocinas pró-inflamatórias (IL-1 $\beta, T N F-\alpha$, IL-6 e PCR), que por sua vez, leva à ativação e geraçăo de EROs por leucócitos e macrófagos, formando assim, um ciclo intimamente associado ao processo de aterosclerose (Pecoits-Filho, 2002; Vaziri, 2004). $O$ aumento na prcdução de EROs pode ocorrer também através da ativação de neutrófilos e monócitos polimorfonucleares pelas toxinas urêmicas (Varizi, 2004; Jung et al., 2004), ou pela bioincompatibilidade com membranas de diálise (Sommerburg et al. 1999; Lucchi et al. 2000; Descamps-Laischa et al., 2001; Kosch, et al.2003).

Estudos relatam o aumento dos niveis de LDLox em hemodialisados, porém, isto é pouco documentado na diálise peritoneal (Futatsuyama et al. 2002; O'Byrne et al.,2001). Westhuyzen, et al. (1997), observaram que a LDL dos pacientes hemodialisados apresenta maior susceptibilidade à oxidação, quando comparada àquela de um grupo de individuos saudáveis. Mimic-Oka et al. (1999) e Clermont $e^{t}$ al. (2000) observaram que o aumento da disfunção renal é acompanhado pela maior formação de MDA, peróxidos lipídicos e peróxido de hidrogênio, ou seja, pacientes hemodialisados estão mais susceptiveis ao estresse oxidativo. Adicionalmente, Muller et al. (2004) investigaram lesão em DNA, níveis de glutationa e MDA de pacientes em $H D$, comparados um grupo controle, e também verificaram que o estress oxidativo está aumentado nos pacientes hemodialisados.

Alteraçðes dos lipídios plasmáticos, apo $B$ e apo $E$, foram avaliadas em pacientes sob diálise peritoneal, observando-se alterações na concentração de 
lipoproteína e modificações na composição química de particulas lipoprotéicas, que podem contribuir para acelerar o processo de aterosclerose nestes pacientes (Horkk;) et al.1994). Canestrari et al.(1995) determinaram as concentrações de MDA, glutationa oxidada e glutationa peroxidase em pacientes sob DP, comparados ao grupo controle, demonstrando que não houve diferença destes marcadores entre os grupos, em contraste aos estudos anteriores. Kim et al. (2000) avaliaram as concentraçōes de MDA e a ca|jacidade antioxidante total do plasma, em relaçăo à albumina, em pacientes sob DP, sugerindo que a peroxidação lipidica estava aumentada nestes pacientes e que isso não estava vinculado à capacidade antioxidante do plasma. Nourooz-Zadeh (1999). comparando grupos de pacientes em tratamento conservador, AD e DP, sugeriram que $o$ aumento do estresse oxidativo pode estar relacionado ao tratamento dialítico e não à doença per se. Analisando a concentrações de LDLox em pacientes sob diálise peritonial e hemodiálise, Futatsuyama et. al. (2002) observaram que os pacientes em DP, especialmente os diabéticos, apresentaram niveis mais elevados de LDLox. Em contraste, alguns estudos não detectaram diferenças na -peroxidação lipidica e nos marcadores de estresse oxidativo em pacientes renais crônicos sob tratamento conservador e hemodiálise, sugerindo não haver correlação entre o aumento do estresse oxidativo e os tipos de tratamento dos pacientes renais crônicos (Belazzi el al., 1993; Prakash et al., 2004).

A concentraçăo de anticorpos anti-LDLox foi determinada no sangue de pacientes urêmicos sob tratamento conservador e hemodiálise por Bergesio et al. (2001), que demonstraram aumento progressivo da peroxidação lipídica em paralelo à diminuição da função renal. Da mesma forma, O'Byrne et al. (2001) observaram um aumento de anticorpos anti-LDLox em pacientes renais crónicos sob hemodiálise e diálise peritoneal, comparados ao grupo controle.

Com relação a $\operatorname{LDL}(-)$, existe apenas um único estudo na literatura, onde Ziouzenkova et al. (1999) verificaram que pacientes hemodialisados (HD) apresentaram aumento de LDL(-) e propuseram um mecarismo de formação da LDL(-) no sangue, durante o processo de hemodiálise, onde o heme da hemoglobina $(\mathrm{Hb})$ poderia ser oxidada para o estado ferril $\left(\mathrm{Fe}^{4+}\right)$ ou perferril $\left(\mathrm{Fe}^{5+}\right)$ pela reação com hidroperóxidos lipídicos ou com $\mathrm{H}_{2} \mathrm{O}_{2}$. Este último pode ser gerado por células inflamatórias, eritrócitos e plaquetas, ou, 
durante a autoxidação da hemoglobina. A oxidação para o estado de Hb-ferril pode ser acompanhada pela formação do radical tirosil (Esquema 1), que poderia mediar reações de adição com outras proteinas.

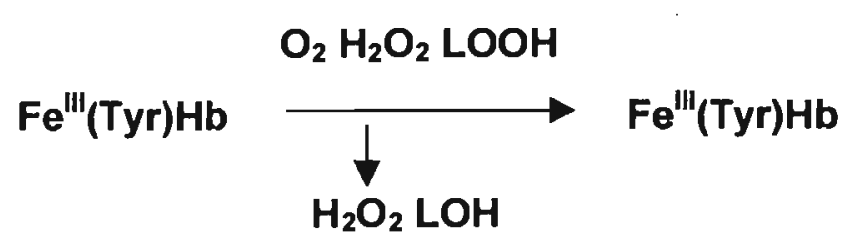

Esquema 1: Autoxidação da hemoglobina (Ziouzenkova et al. 1999)

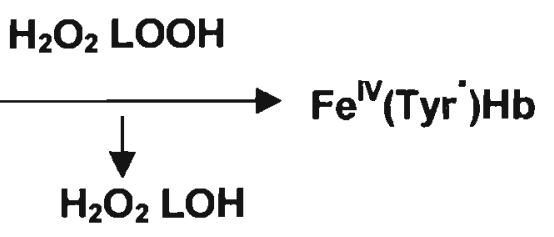

Desta forma, é possivel que a LDL(-) seja formada em parte via ligação covalente com a hemoglobina e a ApoB-100 (Esquema 2) (Ziouzenkova \& Sevanian, 2000).

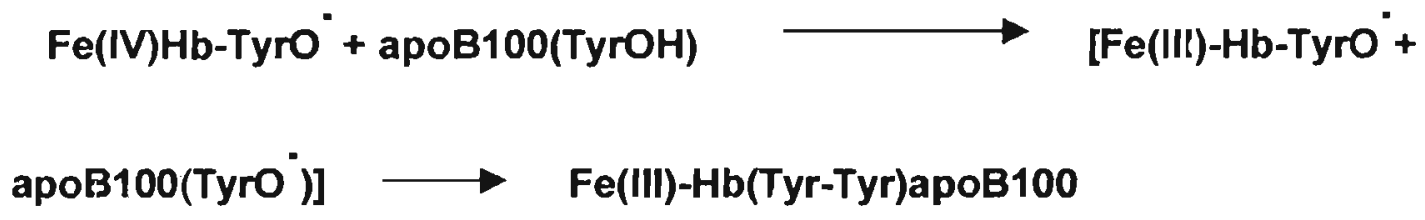

Esquema 2: Reação entre Hemoglobina e ApoB-100 (Ziouzenkova et al. 1999)

O estudo das respostas bioquímicas e imunológicas mediadas pela LDL(-) poderia fornecer informaçōes para se avaliar a progressão da doença e o papel desta subfração como um biomarcador de susceptibilidade de oxidação da LDL nos processos oxidativos in vivo. Considerando que a LDL(-) seja um indicador dos estágios iniciais da oxidação da LDL na circulação sistêmica, sua avaliação no plasma poderia representar uma ferramenta para acompanhar a progressão da aterosclerose nestes pacientes (Oliveira et al., 2006). 


\subsection{Vitamina E e C como antioxidantes na Doença Renal Crônica (DRC)}

O aumento das concentrações de LDL modificada também pode ser explicado pela diminuição dos sistemas de defesa antioxidante (Zwolinska et al., 2006).

O efeito das EROs é balanceado pela ação dos antioxidantes não enzimáticos e enzimáticos. Essas defesas antioxidantes são de extrema importância, pois representam a remoção direta dos radicais livres (pró-oxidantes), promovendo máxima proteção aos sítios biológicos alvos destas espécies. Os antioxidantes podem atuar por diversos mecanismos, tais como: reação especifica com radicais livres ou metais de transição, regeneração de outros antioxidantes, modulação da expressão de genes que codificam as enzimas antioxidantes ou outras vias de proteção antioxidante. Adicionalmente, os antioxidantes devem ter boa biodisponibilidade, ou seja, ser bem absorvidos, atingir uma concentração adequada nos tecidos e fluidos biológicos, protegendo os compartimentos aquosos e/ou lipofílicos (Valko et al., 2006). Baixas concentrações de antioxidantes no plasma favorecem a peroxidação lipídica (Mayer, 2003; Radulescu, 2004).

A vitamina $E$ é uma vitamina lipossolúvel que existe em oito formas diferentes. $O$ $\alpha$-tocoferol, é a forma mais ativa da vitamina $E$ em humanos e é um potente antioxidante biológico presente nas membranas celulares e lipoproteínas. Além de proteger contra a peroxidação lipidica, pode participar de outros mecanismos protetores através da modulação de algumas vias de sinalização celular (Pryor, 2000). A vitamina C (ácido ascórbico) é muito importante, pois atua em ambientes aquosos do organismo, onde regenera o radical $\alpha$-tocoferol em membranas e lipoproteinas (Carr et al., 1999; Kojo, 2004; Retsky et al., 1999).

Lim et al. (2000) mostraram que os niveis de antioxidantes lipossolúveis estão alterados na hemodiálise e podem ser considerados marcadores de risco péra estresse oxidativo nestes pacientes. Loughrey et al.(1994), determinaram as concentrações de MDA, selênio, glutationa peroxidase e vitaminas antioxidantes em pacientes sob tratamento conservador e hemodiálise, sugerindo exacerbação do estresse oxidativo pela hemodiálise, como indicado pelı) aumento da peroxidação lipídica e diminuição jos 
niveis de antioxidantes. Nesta mesma linha, Fiorillo et al. (1998) observaram que pacientes sob hemodiálise apresentam estresse oxidativo devido à diminuição da defesa antioxidante e um aumento da produção de espécies reativas de oxigênio. Aguilera et al. (2002) encontraram diminuição dos niveis intracelulares de vitamina A e E em pacientes hemodialisados. Mayer et al. (2003) verificaram que o aumento da oxidação de lipídios e proteínas pelo processo dialítico foi inversamente proporcional à diminuição dos antioxidantes.

Pelo fato do $\alpha$-tocoferol (vitamina E) ser transferido do soro para os eritrócitos pela HDL, Pastor et al. (1993) analisaram as concentrações de $\alpha$-tocoferol no soro, na HDL e nos eritrócitos de pacientes sob hemodiálise e diálise peritoneal, observando que as concentrações de $\alpha$-tocoferol estavam normais nos dois grupos estudados. Usberti et al. (2002) verificaram a relaçăs entre a gravidade da doença cardiovascular, alguns marcadores de estresse oxidativo e a atividade antioxidante em pacientes sob hemodiálise e diálise peritoneal, demonstrando que existe uma relação entre o grau da peroxidação lipídica e a gravidade da doença cardiovascular em pacientes hemodialisados, mas os niveis de antioxidantes não tiveram relação com a doença carciovascular. Em pacientes hemodialisados, por mais de 20 anos, observou-se niveis normais de vitaminas antioxidantes ( $\mathrm{A}$ E) e aumento de MDA, sugerindo que o estresse oxidativo estava presente nestes pacientes e não estava relacionado com niveis de antioxidantes (Drai et al., 2001).

Sugere-se que a suplementação do alfa-tocoferol possa prevenir doenças cardiovasculares em pacientes renais crônicos, provavelmente através da rejução dos prejuizos causados pelo estresse oxidativo (Amann et al., 2002). Boaz et 'al. (2000) investigaram o efeito da suplementação com vitamina $E$ na doença cardiovascular em pacientes hemodialisados e observaram uma redução de infarto do miocárdio. Da mesma forma, Galli et al. (2001) suplementaram vitamina E em pacier'es hemodialisados e os resultados sugeriram que esta suplementação pode ser importa'ite no combate à peroxidação lipídica nestes pacientes.

Dursun et al. (2002) estudaram os niveis de peroxidaçăo lipídica expressos por TBARS, algumas enzimas antioxidantes e niveis de vitaminas $E$ e $C$ em pacientes renais crônicos sob tratamento conservador e sob hemodiálise em uso de vitaminas 
antioxidantes, observando diminuição dos marcadores de estresse oxidativo em ambos os grupos estudados. Em contraste, a suplementação de pacientes hemodialisados com vitamina $C$, por via oral durante 2 meses, não alterou os marcadores de stresse oxidativo (Fumeron et al. 2006).

Wieczorowska-Tobis et al. (1996) demonstraram que a suplementação intraperitoneal de vitamina $\mathrm{E}$ em ratos sob diálise peritoneal promoveu uma diminuição dos niveis de MDA e aumento da permeabilidade do peritôneo, o que poderia diminuir a efetividade da diálise. Mydlik et al. (2002), ao estudarem a influência da vitamina $E$ (400mg/dia) em alguns parâmetros de defesa antioxidante (superóxido dismutase, glutationa peroxidase, e vitamina A, C e E no plasma) e a peroxidação lipídica (MDA), em pacientes sob diálise peritoneal, concluíram que quando administrada oralmente esta vitamina é um agente antioxidante muito importante, pois houve uma diminuição significativa nos niveis de MDA.

Estudos mostram que a membrana de diálise enriquecida com $\alpha$-tocoferol pode melhorar efetivamente o estresse oxidativo associado à hemodiálise e reduzir suas complicações (Satoh et al., 2001; Baragetti et al., 2006; Sasaki, 2006). Kobayashi et al. (2003) observaram que a vitamina E suplementada através do hemodialisador é muito útil, no ponto de vista clínico, para a melhoria dos riscos para aterosclerose.

Com base na presente revisão, observa-se que há aumento de estresse oxidativo em pacientes renais crônicos, principalmente sob hemodiálise. Estudos sobre o monitoramento da peroxidação lipídica nestes são de extrema importância, visto que o diagnóstico precoce permite a intervenção e pode ajudar a reduzir o desenvolvimento ae doença cardiovascular e manter a qualidade de vida nos pacientes renais crônicos (Kohlhagen \& Kelly, 2003; Snively \& Gutierrez, 2004). 


\section{OBJETIVOS}

\subsection{Objetivo Geral}

(4) Investigar a relação do estado nutricional, avaliado por indicadores antropométricos, com a LDL eletronegativa em pacientes renais crôricos sob hemodiálise e diálise peritoneal.

\subsection{Objetivos Específicos}

$\rightarrow$ Avaliar o estado nutricional antropométrico dos pacientes renais crônicos;

$\stackrel{4}{\rightarrow}$ Verificar as concentrações plasmáticas de $\operatorname{LDL}(-)$, anticorpos ánti-LDL(-) e imunocomplexos (IC) LDL(-)/lgG;

$\rightarrow$ Avaliar as concentraçőes plasmáticas de ascorbato e $\alpha$-tocoferol nestes paciente:

$\rightarrow$ Relacionar as variáveis relativas ao estado nutricional com as concentrações de LDL(-), seus autoanticorpos e imunocomplexos. 


\section{METODOLOGIA}

\subsection{Casuística}

Foram selecionados 25 pacientes com doença renal crônica (DRC) sob hemodiálise, 11 sob diálise peritoneal e 10 indivíduos sem doença renal crônica para compor o grupo controle.

Os pacientes foram atendidos na Clínica de Nefrologia Centro Integrado de Nefrologia (CIN), localizada em Realengo, municipio do Rio de Janeiro. Os pacientes renais crônicos sob hemodiálise realizavam 3 sessões de diálise por semana, com duração de 4 horas cada uma.

Tais pacientes foram selecionados e acompanhados pelo médico e docente do departamento de Clínica Médica da Faculdade de Medicina da UFRJ (Universidade Federal do Rio de Janeiro) Prof. Dr. Maurilo de Nazaré de Lima Leite Junior, nefrologista da clínica.

Os individuos saudáveis foram voluntários da Universidade Federal Fluminense selecionados (UFF) pela Prof ${ }^{\mathrm{a}} \mathrm{Dr}^{\mathrm{a}}$. Denise Mafra, colaboradora do projeto.

Todos os pacientes foram previamente consultados e participaram voluntariamente da pesquisa.

\subsection{Procedimentos Éticos}

O projeto de pesquisa foi aprovado ao Comitê de Ética do FCFUSP, recebendo o número de protocolo CEP $n^{\circ} 324$ (Anexo 1).

\subsection{Critérios de inclusão}

Foram incluídos no estudo todos aqueles pacientes que apresentavam as seguintes caracteristicas: homens e mulheres na faixa etária de 18 a 65 anos, não fumantes. Para os pacientes hemodialisados, foram incluidos apenas os pacientes com fistula arteriovenosa como acesso vascular.

\subsection{Critérios de exclusão}

Foram excluidos pacientes com idade inferior a 18 anos e superior a 65 anos, fumantes, pacientes com doenças autoimune e infecciosa, diabetę melittus, câncer e Aids; pacientes em uso de drogas catabolizantes, uso de cateter para o acesso hemodialítico e de suplementos vitamínicos antioxidantes. 


\subsection{Dados demográficos, clínicos e bioquímicos}

As informações bioquímicas como valores das determinações plasmáticas do colesterol total, HDL-colesterol, LDL-colesterol, VLDL-colesterol e triglicérides, além de dados demográficos e clínicos foram obtidos por análise do prontuário médico e por entrevista com os pacientes.

\subsection{Avaliação Antropométrica}

A avaliação foi realizada por meio dos dados antropométricos: peso (peso seco p/ os dialisados), estatura, prega cutânea tricipital, circunferência braquial e da cintura, área muscular do braço e pelo cálculo do Indice de Massa Corporal (IMC).

A aferição da massa corporal atual foi realizada com auxilio de uma balança calibrada especificamente, da marca FILIZOLA, com capacidade máxima de $150 \mathrm{~kg}$ e subdivisões a cada 100 gramas. $O$ indivíduo era posicionado de pé, no centro da base da balança, descalço e com roupas leves. A estatura foi obtida com o auxilio de um estadiômetro acoplado à balança, referida anteriormente, ficando o indivíquo descalço, com os calcanhares juntos, costas retas e braços estendidos ao lado do corpo.

$O$ estado nutricional foi avaliado segundo o indice de massa corporal (IMC), obtido pela razão entre o peso e o quadrado da estatura, e sua classificação seguiu o proposto pela Organização Mundial de Saúde (OMS, 1995; OMS, 1997). A classificação do estado nutricional segundo o IMC é apresentada no quadro II.

Quadro 11: Estado Nutricional de Adultos seguncio o !MS.

\begin{tabular}{|c|c|}
\hline Classificação & IMC \\
\hline Magreza & $\leq 18,4 \mathrm{~kg} / \mathrm{m}^{2}$ \\
\hline Eutrofia & $18,5-24,9 \mathrm{~kg} / \mathrm{m}^{2}$ \\
\hline Pré-obesidade & $25-29,9 \mathrm{Kg} / \mathrm{m}^{2}$ \\
\hline Obesidade & $\geq 30 \mathrm{Kg} / \mathrm{m}^{2}$ \\
\hline
\end{tabular}

Fonte: OMS, 1995; OMS, 1997. 
Para melhor avaliar a reserva do tecido muscular, devido à correção da área óssea, foi calculada a área muscular do braço corrigida (AMBc) de acordo com a seguinte fórmula:

$A M B c=\left[C B(c m)-(\pi \times P C T(c m)]^{2} / 4 \pi-n\right.$,

sendo $n=6,5$ para mulheres e $n=10$ para homens.

O protocolo para aferição da circunferência do braço seguiu o descrito a seguir. O braço a ser avaliado foi flexionado em direção ao tórax, formando um ângulo de $\iota_{:}^{\circ}$. Em seguida, localizou-se o ponto médio entre o acrômio e olécrano, e foi solicitado ao individuo permanecer com o braço estendido ao longo do corpo com a palma da mião voltada para a coxa. O braço foi então contornado com uma fita flexível no ponto marcado de forma ajustada, evitando compressão da pele ou folga. Para a aferição da prega cutânea tricipital o mesmo ponto médio utilizado para a circunferência do braço foi separado levemente do tecido adiposo do braço não-dominante e foì aplicado o adipómetro da marca Lange (Lohman et al. 1991).

Baseado nos valores de referência estabelecidos por FRISANCHO (1981), a classificação do estado nutricional através da AMBc foi feita de acordo com a Tabela 1.

Quadro Ill: Estado Nutricional de Adultos segundo a AMBc.

\begin{tabular}{|cccc|}
\hline : & Normal & Desnutrição & Desnutrição \\
& & Leve/Moderada & Grave \\
\hline AMBc & Percentil > 15 & Percentil entre 5 e 15 & Percentil < 5 \\
\hline
\end{tabular}

Para avaliar a reserva adiposa, foi utilizada a Prega Cutânea Tricipital (PCT), com método de aferição já citado anteriormente. Os cálculos de adequação foram efetuados para posterior classificação do estado nutricional de acordo com BLACKBURN \& THORNTON (1979), como mostrado na Tabela 2. 
Adequação da PCT (\%) = ((PCT obtida (mm) / PCT percentil 50) x 100)

Quadro IV: Estado Nutricional de Adultos segundo a PCT.

\begin{tabular}{|c|c|c|c|c|c|c|}
\hline & $\begin{array}{c}\text { Desnutrição } \\
\text { Grave }\end{array}$ & $\begin{array}{c}\text { Desnutriçāo } \\
\text { Moderada }\end{array}$ & $\begin{array}{c}\text { Desnutrição } \\
\text { Leve }\end{array}$ & Eutrofia & Sobrepeso & Obesidade \\
\hline PCT & $<70 \%$ & $70-80 \%$ & $80-90 \%$ & $\begin{array}{c}90- \\
110 \%\end{array}$ & $110-120 \%$ & $>120 \%$ \\
\hline
\end{tabular}

Fonte: BLACKBURN \& THORNTON, 1979.

Para analisar o perfil de distribuição de gordura corporal foi aferida a circunferência da cintura. Para isto o paciente devia manter-se em pé e, com auxilio de uma fita métrica não-extensivel, o indivíduo era circundado na linha natural da cintura, na região mais estreita entre o tórax e o quadril, no ponto médio entre a última costela e a crista ilíaca. A leitura era feita no momento da expiração. Os valores obtidos foram comparados com os valores limítrofes associados ao risco de desenvolvimento de complicações relacionadas à obesidade. Para homens este risco. encontra-se aumentado quando os valores de circunferência da cintura são maiores que $102 \mathrm{~cm}$ e para mulheres, quando maiores que $88 \mathrm{~cm}$ (NCEP, 2002).

\subsection{Coleta de sangue}

Foram coletados $15 \mathrm{~mL}$ de sangue em tubos Vacutainer ${ }^{\otimes}$ contendo EDTA como anticoagulante $(1 \mathrm{mg} / \mathrm{mL})$ dos pacientes em jejum de $12 \mathrm{~h}$. Em seguida, o sangue foi centrifugado a $2500 \mathrm{rpm}$ por 10 minutos, a $4^{\circ} \mathrm{C}$, para a obtenção do plasma. Ao plasma foi adicionado um coquetel contendo BHT $100 \mu \mathrm{M}$, Aprotinina $10.0 \mu \mathrm{g} / \mathrm{mL}$, Bénzamidina 10.0 $\mu \mathrm{M}$ e PMSF $5.0 \mu \mathrm{M}$, antes do armazenamento a $-80^{\circ} \mathrm{C}$ até a realização das análises. 


\subsection{Separação da LDL(-)}

\section{Purificação de LDL do plasma}

O sangue foi obtido de voluntários hipercolesterolêmicos, coletado em tubos contendo EDTA e imediatamente centrifugado à $2500 \mathrm{rpm}$ por 10 minutos à $4^{\circ} \mathrm{C}$. $\mathrm{O}$ plasma obtido foi misturado a um coquetel contendo benzamidina $10.0 \mu \mathrm{M}$; PMSF 5.0 $\mu \mathrm{M}$, BHT $100 \mu \mathrm{M}$ e Aprotinina $10.0 \mu \mathrm{g} / \mathrm{mL}$. Em seguida, o plasma foi submetido à ultracentrifugação sequencial à $55.000 \mathrm{rpm}$ por $8 \mathrm{~h}$ à $4^{\circ} \mathrm{C}$ para obtenção da LDL, utilizando-se uma ultracentrifuga Sorval ${ }^{\circledR}$, modelo Ultra Pro 80 , com um rotor T-127.0. A $\mathrm{LDL}$ isolada foi dializada contra tampão tris-HCL, $\mathrm{pH} 7,4$, conłendo EDTA, à ; $;{ }^{\circ} \mathrm{C}$, durante 4 horas com trocas sucessivas do tampão a cada hora (Redgrave et al., 197, j).

Obtenção da LDL (-) por cromatografia líquida (FPLC) Fast Protein Liquid Chromatography

O isolamento da LDL (-) foi realizado por FPLC com uma coluna UNO Q1(Bio Rad). O procedimento foi iniciado com a lavagem da coluna com $300 \mathrm{ml}$ do tampão $B$ (10 mınol/L tris-HCL, $1 \mathrm{~mol} / \mathrm{L} \mathrm{NaCl}, 1 \mathrm{mmol} / \mathrm{L}$ EDTA, pH 7,4) e depois equilibrada com $300 \mathrm{ml}$ de tampão $A(10 \mathrm{mmol} / \mathrm{L}$ tris- $\mathrm{HCL}, 1 \mathrm{mmol} / \mathrm{L}$ EDTA, $\mathrm{pH}$ 7,4). A LDL foi dializada contra o tampão $A$, sendo então injetada na coluna (antes da injeção na coluna a LDL foi filtrada com 2 filtros diferentes, 0,45um e 0,22 um para evitar entupimento da coluna). O procedimento cromatográfico estabeleceu-se um fluxo de $4 \mathrm{ml} / \mathrm{min}$ em diferentes gradientes: 0 a $100 \mathrm{ml}: 0 \%$ tampão $A ; 100$ a $200 \mathrm{ml}$ gradiente continuo: 0 a 10 \% tampão B; 200 a 400 ml: $22 \%$ tampão B; 400 a 600 ml: $50 \%$ tampão B; 600 a 800 $\mathrm{ml}: 100 \%$ tampão B (De Castellarnau et al., 2000). 


\section{Eletroforese de lipoproteinas}

A eletroforese foi realizada com a aplicação de 0,5 ul de cada fração de LDL, separada por FPLC, em gel de agarose utilizando-se kit comercial (Celm; CELMGEL ${ }^{8}$ ) com o tampão tris, $\mathrm{pH} 9,5$ a 100 volts. O tempo de corrida eletroforética foi de 14 minutos. O corante do gel utilizado foi Amido Black.

\subsection{Determinação da concentração de LDL(-)}

\section{Método de ELISA com anticorpos monoclonal e policlonal (ELISA-misto)}

Placas de imunoensaio de 96 poços (EIA/RIA, Costar, Cambridge, MA, USA) foram sensibilizadas com $50 \mathrm{uL}$ de anticorpo policlonal de coelho anti-LDL eletronegativa (10 $\mathrm{ug} / \mathrm{mL}$ ) diluido com tampão carbonato-bicarbonato $0,1 \mathrm{M}, \mathrm{pH} 9,4$, e incubadas overnight a $4^{\circ} \mathrm{C}$. Após este período, o excesso de anticorpo foi removido e as ${ }_{,}$placas foram bloqueadas com leite desnatado 5\% em PBS (tampão fosfato) e armazenadas em estufa a $37^{\circ} \mathrm{C}$ por 1 hora e meia. Em seguida, as placas foram lavadas em 3 ciclos de 200 uL por well com tampão de lavagem (PBS-Tween 0,05\%) (pH 7,4). Posteriormente, $50 \mu \mathrm{L}$ de amostras dos soros dos grupos estudados foram previamerite diluídas $\mathrm{em}$ PBS $5 \%$ de leite desnatado (1:10) e distribuídas na placa e incubada à $37^{\circ} \mathrm{C}$ por 90 minutos, em triplicata. A seguir, a placa foi lavada conforme descrito acima, adicionando-se posteriormente $50 \mu \mathrm{L}$ de anticorpo monoclonal anti-LDL(-) biotinilado (descrição abaixo) (diluído 1:1000 em PBS) com incubação de 90 minutos à $37^{\circ} \mathrm{C}$. Após a lavagem, foram adicionados $50 \mu \mathrm{L}$ de streptavidina marcada com peroxidase (Stressgen Biotechnologies Corp.), diluída com PBS (1:1000) e incubado durante 1 hora. Após a lavagem da placa, foram adicionados a mistura de isoluminol e $\mathrm{H}_{2} \mathrm{O}_{2}(0,25$ $\mu \mathrm{L} / \mathrm{mL}$ isoluminol). A leitura ca quimiluminescência produzida foi reali.yada imediatamente, utilizando-se uma leitora de placas de ELISA para quimiluminescincia (LumiCount, Packard Meriden, USA). A análise quantitativa foi realizada utilizancio-se curvas padrão de $\mathrm{LDL}^{-}$em cada placa, em triplicata. A curva padrão foi feita a partir das preparações com LDL(-) humana nas faixa de diluições de 1/1, 1/2, 1/4, 1/20 e 1/100. 


\section{Biotinilização do Anticorpo Monoclonal Anti-LDL(-)}

O Anticorpo Monoclonal anti-LDL(-) foi dialisado com tampão Borato de Sódio $0,1 \mathrm{M}$, $\mathrm{pH} 8,8$, durante 12 horas. A seguir foi adicionado ao anticorpo $1 \mathrm{mg}$ de biotina (éste de D-biotinoil-e-ácido aminocaproic-N-hidroxisuccinimida) dissolvida em $100 \mu \mathrm{L}$ de dimetilsulfóxido (DMSO), nas seguintes proporçőes $250 \mu \mathrm{g}$ biotina/mg anticorpo. A mistura foi mantida em temperatura ambiente por 4 horas. Após este período foi adicior lado $1 \mathrm{M} \mathrm{NH}_{4} \mathrm{Cl}$ por 10 minutos. Finalmente, o anticorpo foi dialisado em $\mathrm{PBS} \mathrm{pH}$ 7,4 .

\subsection{Determinação de anticorpos anti-LDL eletronegativa}

A determinação dos anticorpos foi realizada através de imunoensaio ELISA (Damasceno, 2006). Alíquotas da LDL eletronegativa foram diluídas:.em tampão carbonato-bicarbonato $0,1 \mathrm{M}, \mathrm{pH} 9,4$, até a concentração final de 1 ug/poço. Após o preparo das amostras, placas de 96 poços (EIAVIA, Costar, Cambridge, MA, USA) foram sensibilizadas e incubadas overnight à $4^{\circ} \mathrm{C}$. Em seguida, o sobrenadante foi descartado, sendo os sítios livres bloqueados com leite desnatado a $5 \%$ diluído em tampão fosfato (PBS), pH 7,4. As placas foram incubadas em estufa à $37^{\circ} \mathrm{C}$ por 1 hora e meia. Em seguida as placas foram lavadas 3 vezes com PBS-Tween $(0,05 \%)$. Após esta etapa, as amostras de plasma foram diluídas em leite desnatado PBS 1\% (1:100). Foram adicionados $50 \mathrm{uL}$ de cada amostra/poço, incubando-se por 2 horas à $37^{\circ} \mathrm{C}$. Em seguida, as placas foram lavadas, conforme descrito acima. Posteriormente, foram adicionados 50uL/poço do anticorpo anti-igG humana marcado com peroxidase $(1: 4000)$ diluído em leite $1 \%$-PBS, sendo as placas incubadas por 1 hora à $37^{\circ} \mathrm{C}$. Após este período, as placas foram lavadas e reveladas com OPD 1 pastilha para $5 \mathrm{~mL}$ de tampão (tampão citrato fosfato e $0,25 u L$ de $\mathrm{H}_{2} \mathrm{O}_{2} / \mathrm{mL}$ ) e bloqueadas com $50 \mu \mathrm{L}$ well de $\mathrm{H}_{2} \mathrm{SO}_{4}$. As placas foram incubadas à temperatura ambiente, sendo a absorbância monitorada a $490 \mathrm{~nm}$. Os resultados foram apresentados como equivalentes de lgG anti-LDL eletronegativa (absorbância aplicada à equação da curva padrăo, sendo o 
valor obtido multiplicado pelo título). A curva padrăo foi feita a partir das preparações com IgG total humana (10 mg/mL; marca Rockland) nas faixa de diluições de $1 / 10$ a $1 / 500$.

\subsection{Detecção de imunocomplexos}

A presença de imunocomplexos dos grupos estudados, foi realizada por ELISA (Tinahones et al. 2005). Brevemente, placas de polivinil (Costar) de 96 orificios foram sensibilizadas com $10 \mu \mathrm{g} / \mathrm{ml}$ de anticorpo policlonal de coelho fragmentado (porção Fab) diluído em PBS, $50 \mu \mathrm{l} /$ poço e mantido overnight a $4^{\circ} \mathrm{C}$. Depois do bloqueio com PBS contendo $5 \%$ de leite desnatado por 2 horas a temperatura ambiente $200 \mu l / p o c ̧ o$, as placas foram incubadas com soro dos grupos estudados diluído 1/50 em PBS (50 $\mu /$ poço) por 3 horas, à temperatura ambiente. Após este período adicionou-se $50 \mu l / p o c ̧ o$ de anti-lgG humano conjugada a peroxidase por 1 hora a temperatura ambiente. A revelação foi feita com $50 \mathrm{ul} /$ poço (OPD, $1 \mathrm{mg} / \mathrm{ml}$, Sigma), dișsolvido em tampão citrato-fosfato $100 \mathrm{mM}$ pH5,8, contendo $0,05 \%(\mathrm{v} / \mathrm{v})$ de $\mathrm{H}_{2} \mathrm{O}_{2}$. A reação foi interrompida, após o aparecimento de cor, com $50 \mu \mathrm{l} / /$ poço de $\mathrm{H}_{2} \mathrm{SO}_{4} 4 \mathrm{~N}$. Os resultados foram avaliados por leitura espectofotométrica em comprimento de onda de $492 \mathrm{~nm}$. Entre cada etapa as placas foram lavadas 3 vezes com PBS-tween 0,01\% (200 $\mu 1 /$ po: $: 0)$. 


\subsection{Determinação de ascorbato e $\alpha$-tocoferol}

A concentração de alfa-tocoferol nas amostras de plasma dos pacientes foi determinada por cromatografia líquida de alta resolução (HPLC). A extração dos antioxidantes lipossolúveis do plasma foi realizada pela adição de $0,25 \mathrm{ml}$ de SDS 4 $\mathrm{mM}$ a $0,25 \mathrm{ml}$ de amostra (plasma) em um tubo de extração protegido da luz, agita.ıdose por 10 segundos no vortex; em seguida foi adicionado $1 \mathrm{ml}$ de metanol, agitando-se novamente por 1 minuto. A seguir, foi adicionado $1,5 \mathrm{ml}$ de hexano contendo $\mathrm{BHT}(0,5$ g/l) e agitou-se por 2,5 minutos; o material foi centrifugado por 10 minutos a $2500 \mathrm{rpm}$ e o sobrenadante retirado (hexano) para evaporação no nitrogênio. Após secagem, foi

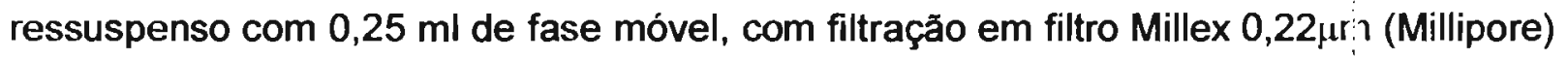
e foram injetadas no cromatógrafo. A determinação dos antioxidantes łipossolúveis foi feita utilizando-se o sistema cromatográfico com detector eletroquimico coin potencial de $+600 \mathrm{mV}$ (deteç̧ão de alfa-tocoferol). A coluna utilizada foi a de fase reversa $\mathrm{C} 18$ CG Nucleosil (CG do brasil S/A) som fluxo de $1,0 \mathrm{~mL}$ por minuto da fase $\mathrm{m}$; jvel composta por metanol:acetonitrila:clorofórmio $(35: 35: 30, \mathrm{v} / \mathrm{v} / \mathrm{v})$ ccntendo perclorati de lítio $20 \mathrm{mM}$ (necessária para a detecção eletroquímica). A curva de calibração 'dos antioxidantes lipossolúveis e a quantificação das amostras foi estabelecida com injeção de $20 \mu \mathrm{L}$ (Thurnhan et al., 1988).

A análise das concentraçōes plasmáticas do ascorbato foi determinada por HPLC com detector eletroquímico (potencial $=+600 \mathrm{mv}$ ). As proteínas do plasma forma precipitadas com ácido perclórico 0,75\% (Tsao Salimi, 1981) e o sobrenadante foi filtradc em membranas com poros de $22 \mu \mathrm{m}$ e injetado no cromatógrafo $\left(20_{\mu}\right.$ ll), através do injetor automático SIL-10A (Shimadzu). A quantificação das amostras foi feita com padrōes externos, através de curvas de calibração com niveis múltiplos. Foi utilizado o mesmo sistema cromatográfico anterior, com uma coluna de fase reversa $C_{18} C G$ Nucleosil (CG do Brasil SVA). A fase móvel foi composta d€ acetato de sódio trihidratado $(0,04 \mathrm{M})$, decilamina $(1 \mathrm{~mL})$ e EDTA $(0,200 \mathrm{gll})$ em $950 \mathrm{ml}$ de água deionizada; ácido acético glacial foi adicionado até atingir-se pH 5 e o volume foi completado para 1 litro com água deionizada. $O$ fluxo da fase móvel foi de $1 \mathrm{~mL} /$ minuto para todas as análises. 
As concentrações plasmáticas de alfa-tocoferol foram normalizadas pelo conteúdo de colesterol da seguinte forma: Dividiu-se os valores das concentraçð̃es de alfa-tocoferol plasmático $(\mu \mathrm{M})$ por 10 para se obter a concentração em $\mu \mathrm{moles} / \mathrm{dL}$ e em seguida dividiu-se diretamente pela concentraçăo de colesterol, $(\mathrm{mg} / \mathrm{dL})$, obtendo-se a concentração de alfa-tocoferol em $\mu \mathrm{moles} / \mathrm{mg}$ de colesterol.

\subsection{Análise Estatística}

Os resultados foram expressos em média \pm DP (Desvio padrão) ou mediana (máx.- min.). Foi utilizado One-Way ANOVA (ou Kruskal-Wallis, quando apropriado) para comparações, e o teste de Bonferroni foi utilizado para análises posteriores. As correlaçðes entre as variáveis do estudo foram determinadas pelo coeficiente de correlação de Spearman. Os resultados estatisticamente significantes foram aceitos com $p<0.05$. As análises estatísticas foram realizadas utilizando-se o programa SPSS 11.0. 


\section{RESULTADOS}

\subsection{Ca racterísticas dos grupos}

As características dos grupos estudados estão apresentadas na tabela 1. Hipertensão arterial sistêmica (HAS) foi a causa de DRC em $72 \%$ dos pacientes sob HD e $90.9 \%$ sob DP. Não houve diferença significativa no tempo de diálise.

Tabela 1: Características gerais dos grupos estudados.

\begin{tabular}{c|c|c|c}
\hline Parâmetros & HD $=25$ & DP =11 & Controles =10 \\
\hline $\begin{array}{c}\text { Sexo F/M } \\
\text { Idade (anos) }\end{array}$ & $13 / 12$ & $9 / 2$ & $7 / 3$ \\
\hline Causa da doença & $48,1 \pm 8,4^{\mathrm{a}}$ & $55,1 \pm 6,3^{\mathrm{a}}$ & $42,2 \pm 12,5$ \\
HAS & & & - \\
RP \\
GC
\end{tabular}

$(H A S)=$ Hipertensâo arterial siste̊mica; $(R P)=$ Rins policlsticos; $(G C)=$ Glomerulonefrite crônica

a diferença entre os grupos $p=0,002$. 


\subsection{Dados Antropométricos dos Participantes do Estudo}

A tabela 2 mostra o estado nutricional dos grupos estudados. Em relação ao IMC, 17 pacientes HD, 4 DP e 6 controles foram classificados como normais. Apenas 1 dos pacientes sob DP, foi considerado como moderadamente desnutrido. Foram considerados com sobrepeso e obesidade, 4 sob HD, 6 sob DP e 3 controles.

De acordo com a massa de gordura avaliada pelo PCT, 12 dos pacientes sob HD, 4 sob DP e 2 controles estavam abaixo do percentil 5. Sete HD, 7 DP e 2 controles apresentaram valores de circunferência da cintura acima dos valores recomendados.

Com relação à massa magra avaliada pela $A M B, 4$ dos pacientes $H D, 1$ DP e 3 controles estavam entre os percentis 5 e 15, enquanto 3 dos pacientes HD e 2i DP estavam abaixo do percentil 5 . Os demais estavam dentro da normalidade.

Tabela 2: Dados Antropométricos dos grupos estudados

\begin{tabular}{c|c|c|c}
\hline 'Srupos & $\mathrm{HD}(\mathbf{N}=25)$ & $\mathrm{DP}(\mathbf{N}=11)$ & Controle(N=9) \\
\hline $\mathrm{IMC}\left(\mathrm{kg} / \mathrm{m}^{2}\right)$ & $23,1 \pm 3,0$ & $24,7 \pm 4,1$ & $23,8 \pm 3,9$ \\
$\mathrm{CC}(\mathrm{cm}) \mathrm{M} / \mathrm{F}$ & $83,5 \pm 18,3 /$ & $97,7 \pm 10,2 /$ & $105,5 \pm 12,3 /$ \\
& $83,5 \pm 15,2$ & $82,16 \pm 11,2$ & $75,5 \pm 10,4$ \\
& $13,4 \pm 5,0^{\mathrm{ab}}$ & $19 \pm 4,5^{\mathrm{b}}$ & $18,2 \pm 4,1^{\mathrm{a}}$ \\
AMB $(\mathrm{mm})$ & $27,3 \pm 4,0$ & $28,7 \pm 4,7$ & $29 \pm 4,0$ \\
\hline
\end{tabular}

\footnotetext{
diferença entre grupos $p=0,04$;

${ }^{b}$ diferença entre os grupos $p=0,01$.
} 


\subsection{Perfil Lipidico}

As alterações no perfil lipidico segundo a IV Diretriz Brasileira sobre Dislipidemias e Prevenção da Aterosclerose (Departamento de Aterosclerose da Sociedade Brasileira de Cardiologia, 2007), podem ser vistas no Gráfico 1, onde está apresentada a porcentagem dos pacientes que tinham baixas concentrações de HDL e concentrações elevadas de LDL-colesterol, colesterol total e triglicérides (TG). Na tabela 3 está apresentado o perfil lipídico dos grupos estudados.

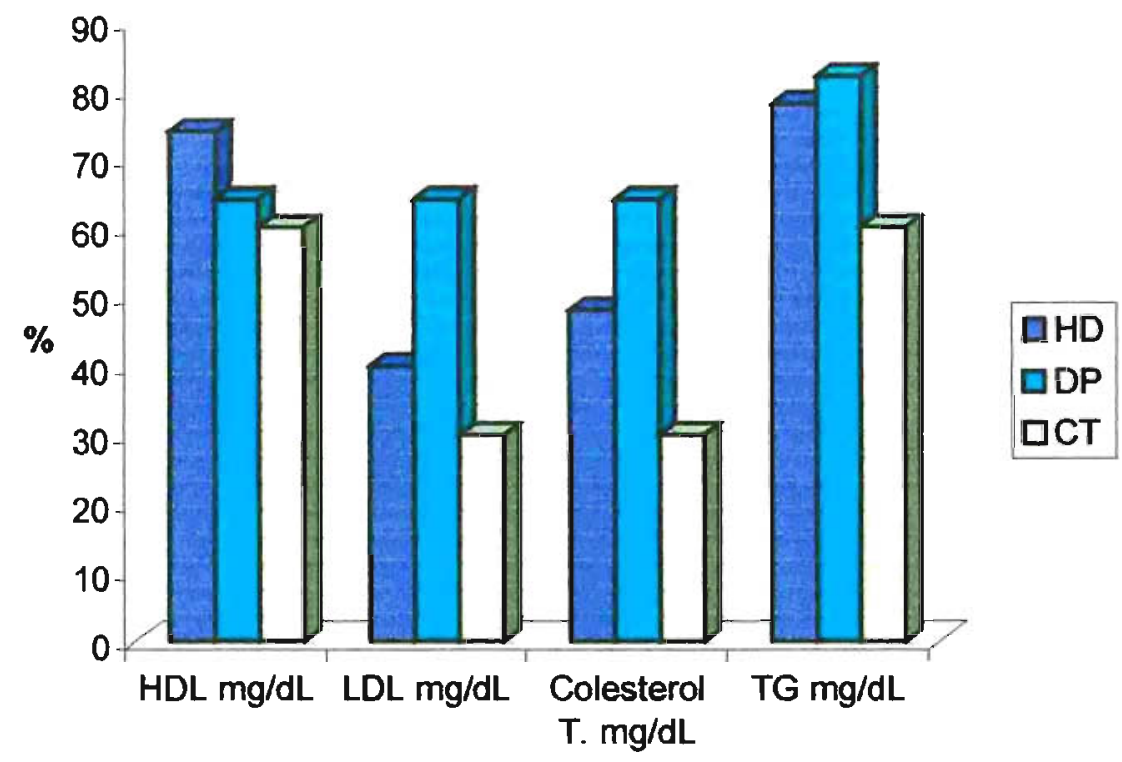

Gráfico 1: Porcentagem dos pacientes com baixas concentrações de HDL-colesterol e concentrações elevadas de LDL-colesterol, colesterol total e triglicérides (TG).

Tabela 3: Perfil Lipídico dos grupos estudados

\begin{tabular}{c|c|c|c|c}
\hline Grupos & HD & DP & Controles & $\begin{array}{c}\text { Valores de } \\
\text { referência }\end{array}$ \\
\hline Colesterol Total & $194 \pm 36$ & $218 \pm 34$ & $186 \pm 38$ & $<200$ \\
(mg/dL) & & & & \\
HDL-c (mg/dL) & $35 \pm 7$ & $39 \pm 10$ & $33 \pm 13$ & $>40$ \\
LDL-c (mg/dL) & $117 \pm 44$ & $141 \pm 33$ & $127 \pm 34$ & $<130$ \\
VLDL-c (mg/dL) & $43 \pm 26$ & $38 \pm 13$ & $30 \pm 8$ & $<30$ \\
Triglicerídeos (mg/dL) & $217 \pm 130$ & $189 \pm 64$ & $151 \pm 38,2$ & $<150$ \\
\hline
\end{tabular}




\subsection{LDL eletronegativa}

As concentrações de LDL(-) nos pacientes HD (576 $\pm 233 \mu \mathrm{g} / \mathrm{mL})$ foram significativamente maiores quando comparadas às dos pacientes DP $(223 \pm 118 \mu \mathrm{g} / \mathrm{mL})$ e controles $(55 \pm 33 \mu \mathrm{g} / \mathrm{mL}) \quad(p<0,00001)$. (Gráfico 2). Observou-se que as concentrações de LDL(-) nos pacientes sob HD e DP foram 10 vezes e 5 vezes (respectivamente) superiores às do grupo controle.

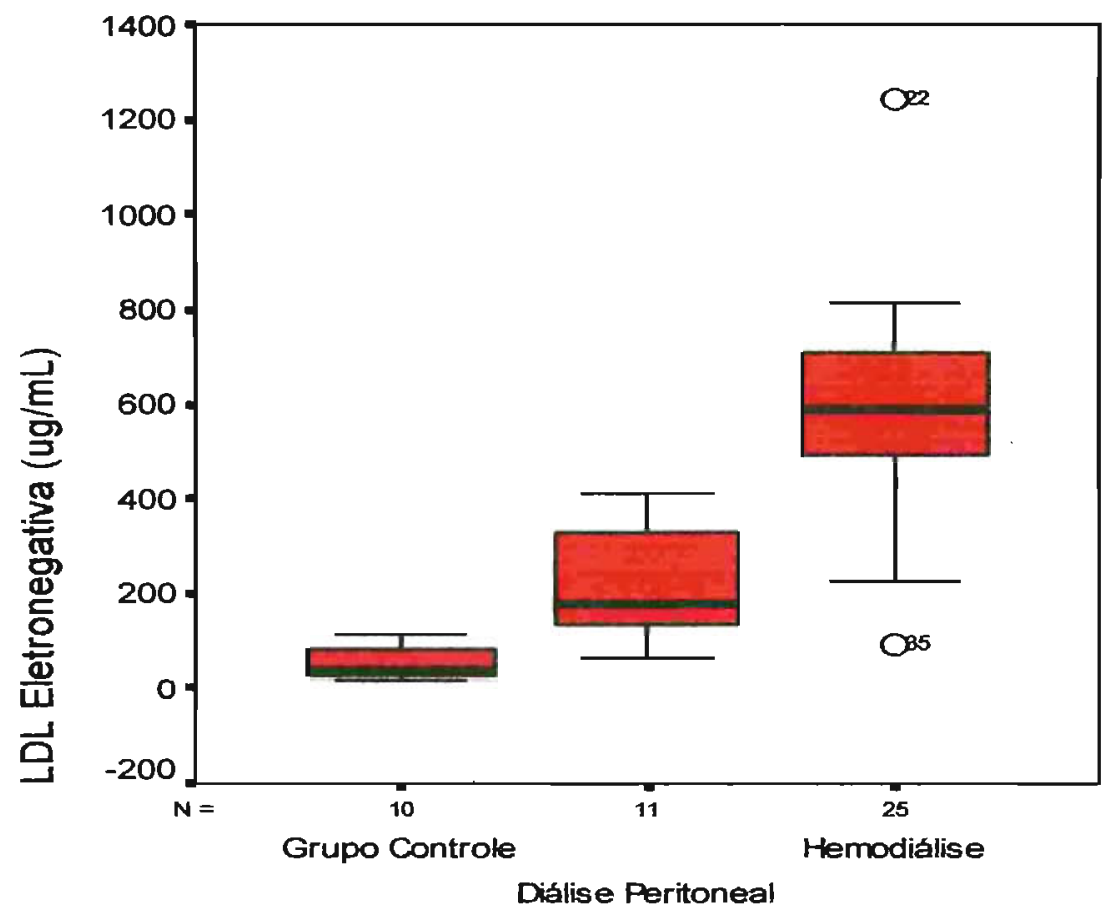

Gráfico 2: Concentrações de LDL (-) $(\mu \mathrm{g} / \mathrm{mL})$ nos grupos estudados. 


\subsection{Auto anticorpo anti LDL(-)}

As análises mostraram que o grupo controle teve uma concentração maior do auto-anticorpo anti-LDL(-) $\lg G(0,36 \pm 0,09 \mu \mathrm{g} / \mathrm{ml})$, quando comparado aos grupos DP $(0,28 \pm 0,12 \mu \mathrm{g} / \mathrm{mL})(p<0,003)$ e HD $(0,2 \pm 0,1 \mu \mathrm{g} / \mathrm{mL})(p<0,001)$. (Gráfico 3).

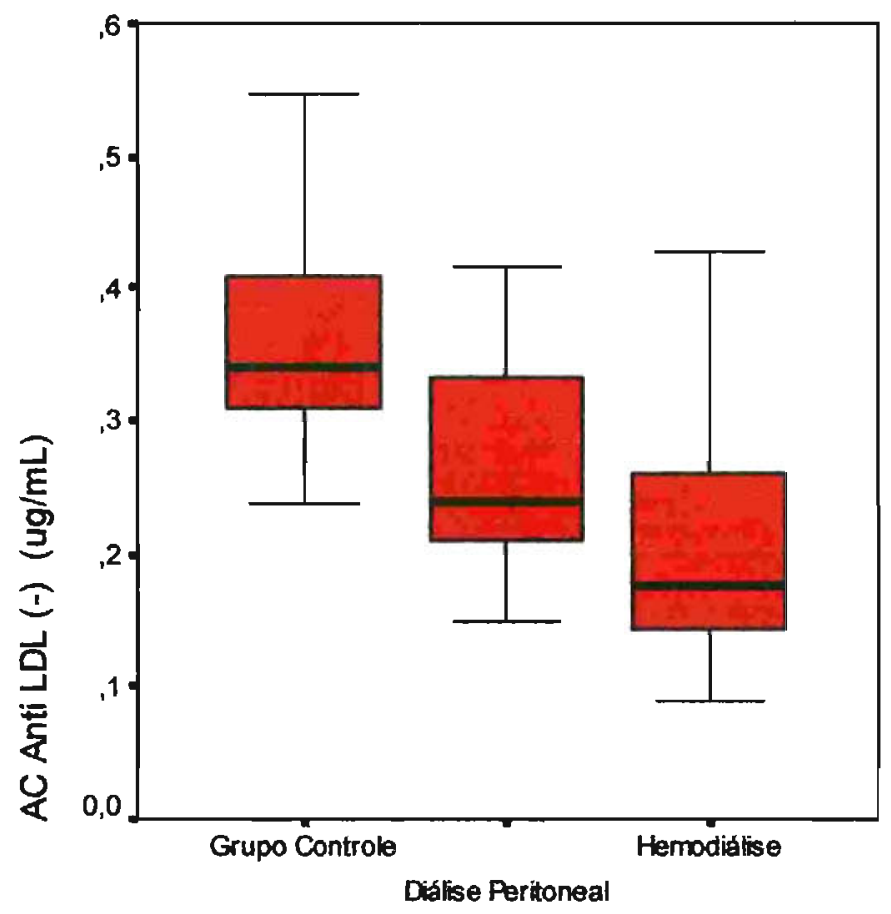

Gráfico 3: Concentraçōes de Anti-LDL (-) lgG auto-anticorpos ( $\mu \mathrm{g} / \mathrm{mL})$ nos grupos estudados. 


\subsection{Imunocomplexos}

Os níveis de Imunocomplexos (IgG- LDL-) no grupo controle $(0,35 \pm 0,20 \mu \mathrm{g} / \mathrm{mL})$ foram significativamente maiores comparados aos grupos $H D \quad(0,15 \pm$ $0,07 \mu \mathrm{g} / \mathrm{mL})(p<0,00001)$ e DP $(0,22 \pm 0.07 \mu \mathrm{g} / \mathrm{mL})(p<0,009)($ Gráfico 4$)$.

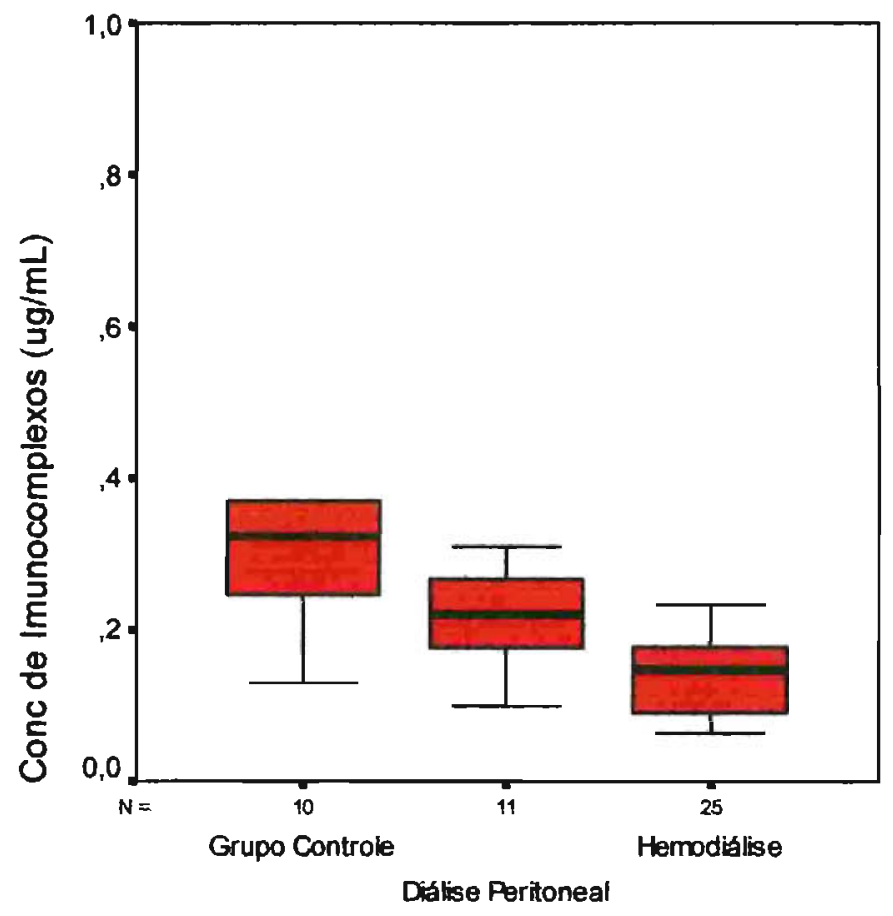

Gráfico 4: Concentrações de Imunocomplexos LDL(-)/lgG $(\mu \mathrm{g} / \mathrm{mL})$ nos grupos estudados. 


\subsection{Ascorbato Plasmático}

As concentrações plasmáticas de ascorbato de pacientes hemodialisados (138 \pm $43 \mu \mathrm{M}$ ) foram maiores comparados aos dos pacientes sob diálise peritoneal (105 \pm $26 \mu \mathrm{M}$ ) e controles (98 $\pm 36 \mu \mathrm{M}$ ). (Gráfico 5). As concentrações de ascorbato em todos os pacientes estavam dentro dos valores referéncia $(>23 \mu \mathrm{M})$.

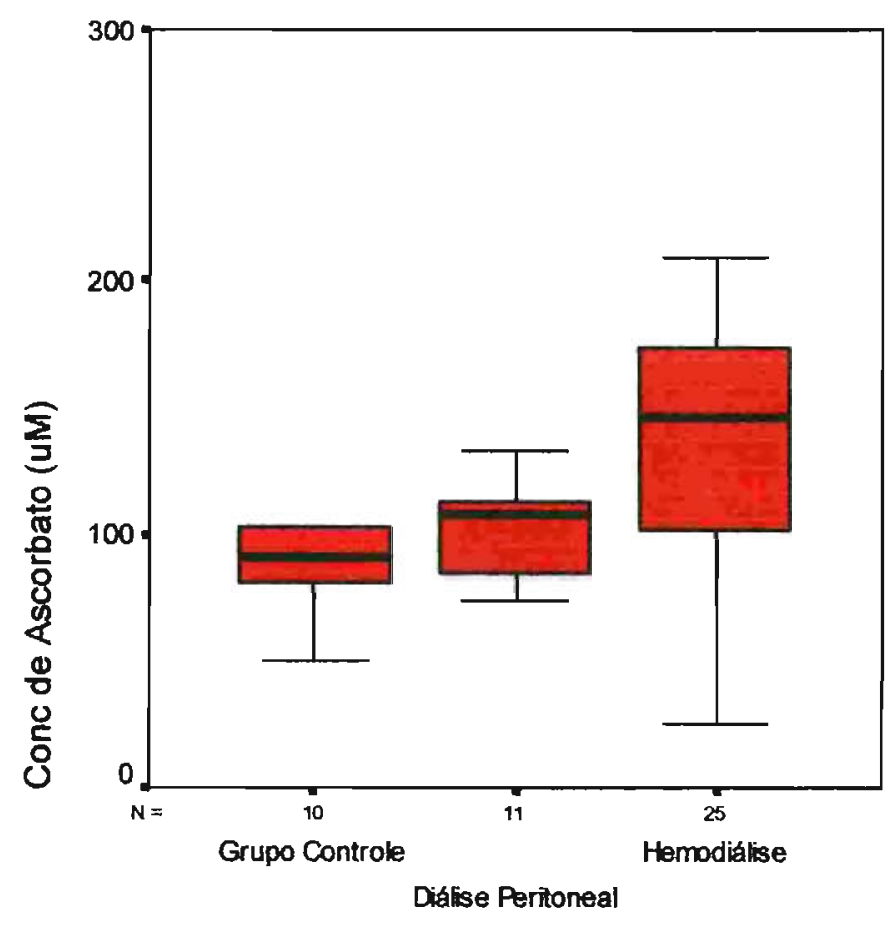

Gráfico 5: Concentrações de ascorbato plasmático $(\mu \mathrm{M})$ nos grupos estudados. 


\subsection{Alfa-Tocoferol plasmático}

Não houve diferença estatística para as concentrações plasmáticas de alfatocoferol entre os grupos estudados, após a correção pelas concentrações de colesterol ( $\mu$ moles alfa-tocoferol /mg de colesterol (Tabela 4).

Tabela 4: concentração de tocoferol em umoles/mg de colesterol

\begin{tabular}{c|c}
\hline Grupos & $\begin{array}{c}\text { concentração de tocoferol em } \mu \mathrm{moles} / \mathrm{mg} \text { de } \\
\text { colesterol }\end{array}$ \\
\hline HD & $0,2 \pm 1,3$ \\
DP & $0,9 \pm 1,5$ \\
CT & $1,2 \pm 2,8$ \\
\hline
\end{tabular}

\subsection{Correlações}

As análises de correlação demonstraram que os valores de ṕrega cutãnea tricipital (PCT) se correlacionaram diretamente com as concentraçőes plasmáticas dos imunocomplexos $(r=0,37 ; p=0,01)$ (Gráfico 6) e inversamente corn as concentrações plasmáticas de $\operatorname{LLL}(-)(r=-0,37 ; p=0,018)$ (Gráfico 7). As concentrações plasmáticas clos anticorpos IgG anti-LDL(-) se correlacionaram diretamente com os valores do IMC $(r=0,83 p=0,00001)$ (Gráfico 8) e da circunferência da cintura (Gráfico 9) $(r=0,75 p=$ $0,0001)$. Houve correlação negativa entre as concentrações de LDL(-) e dos anticorpos IgG anti-LDL(-) (r= -0,43; $p=0,003)$ como mostra o gráfico 10 . Não houve correlação entre IMC e LDL(-) no presente estudo. 


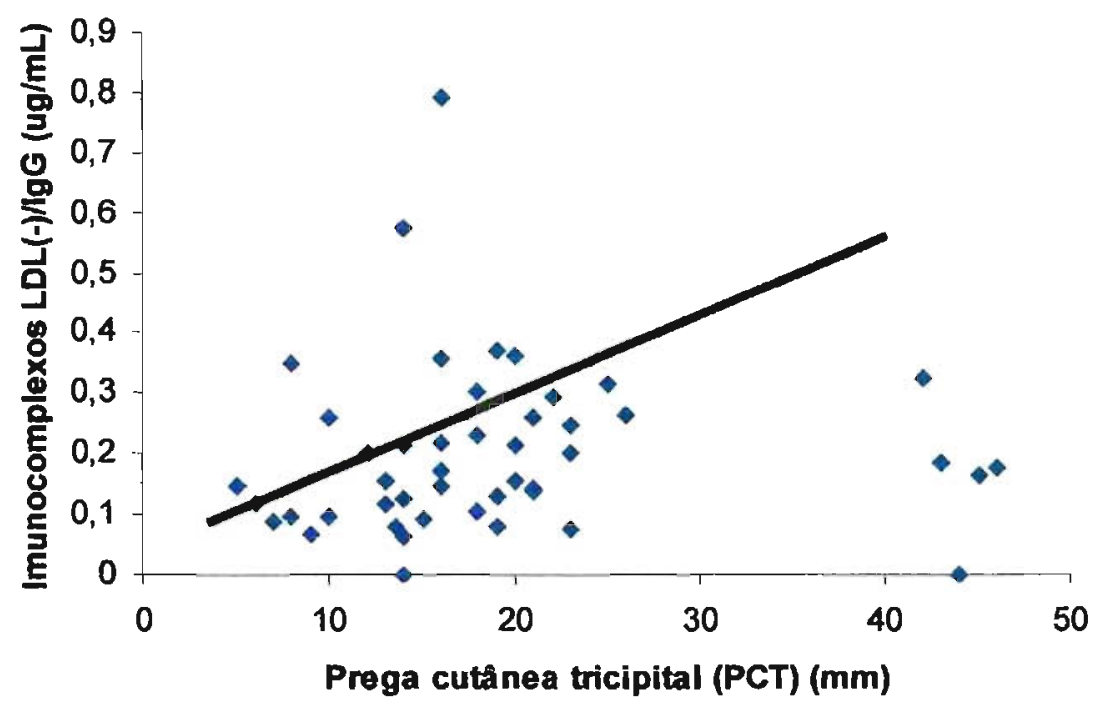

Gráfico 6: Correlação entre Imunocomplexos LDL(-)/lgG $(\mu \mathrm{g} / \mathrm{mL})$ e PCT $(\mathrm{mm})$.

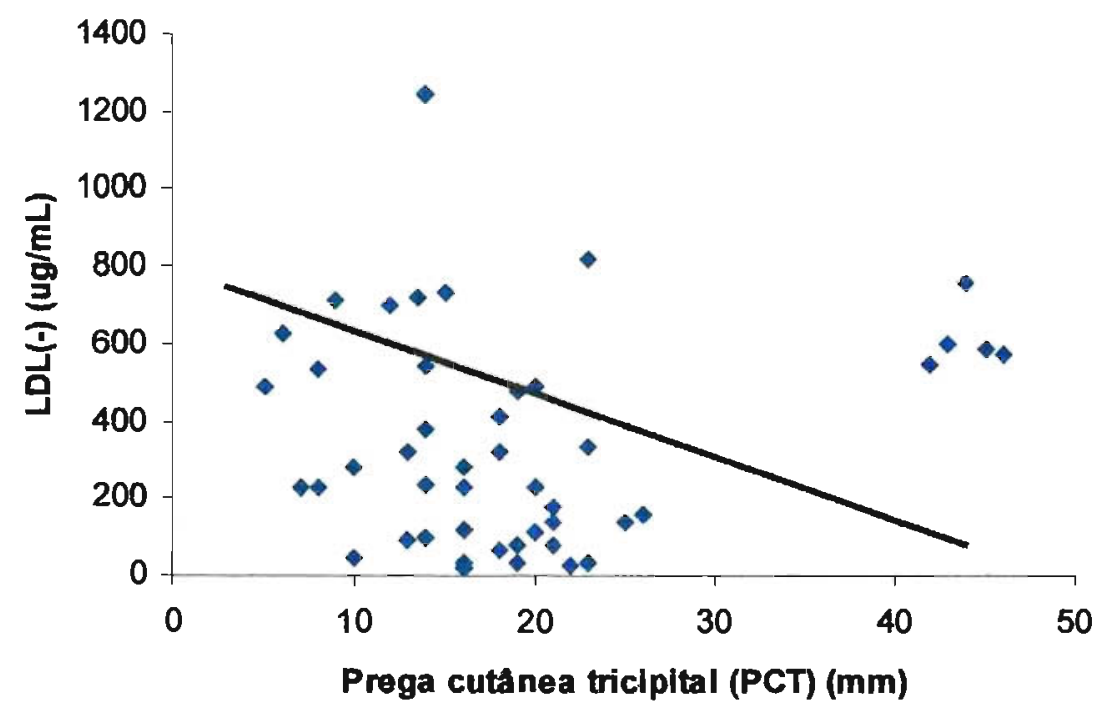

Gráfico 7: Correlação entre LDL(-) $(\mu \mathrm{g} / \mathrm{mL})$ e PCT (mm). 


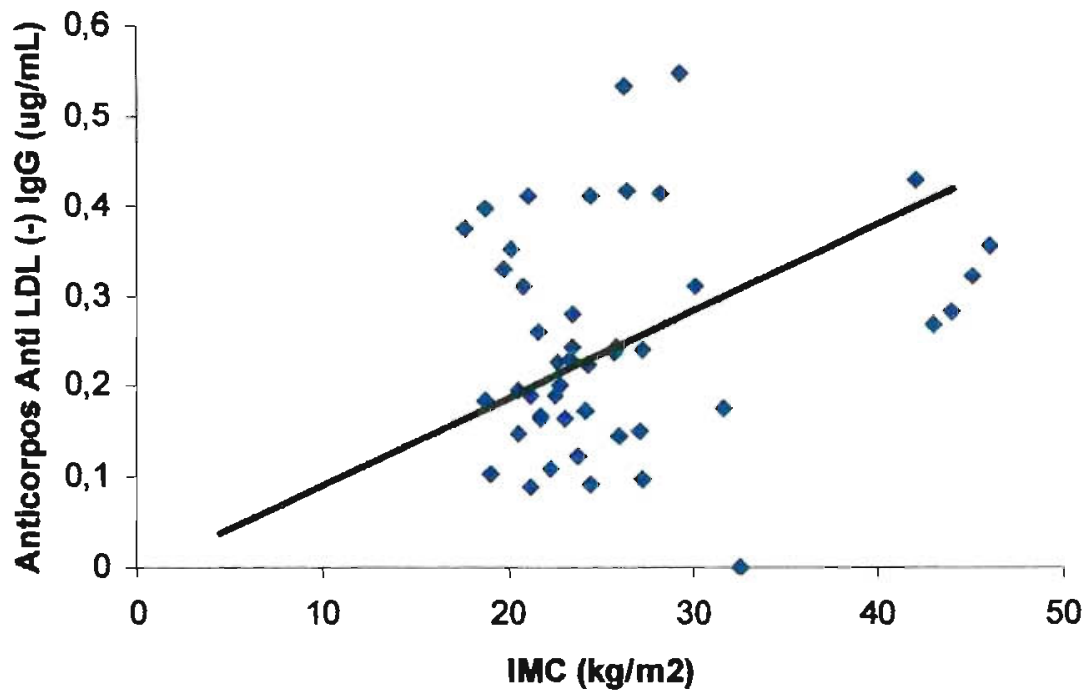

Gráfico 8: Correlação entre anticorpos $\lg G(\mathrm{ug} / \mathrm{mL})$ anti LDL(-) e IMC $\left(\mathrm{Kg} / \mathrm{m}^{2}\right)$.

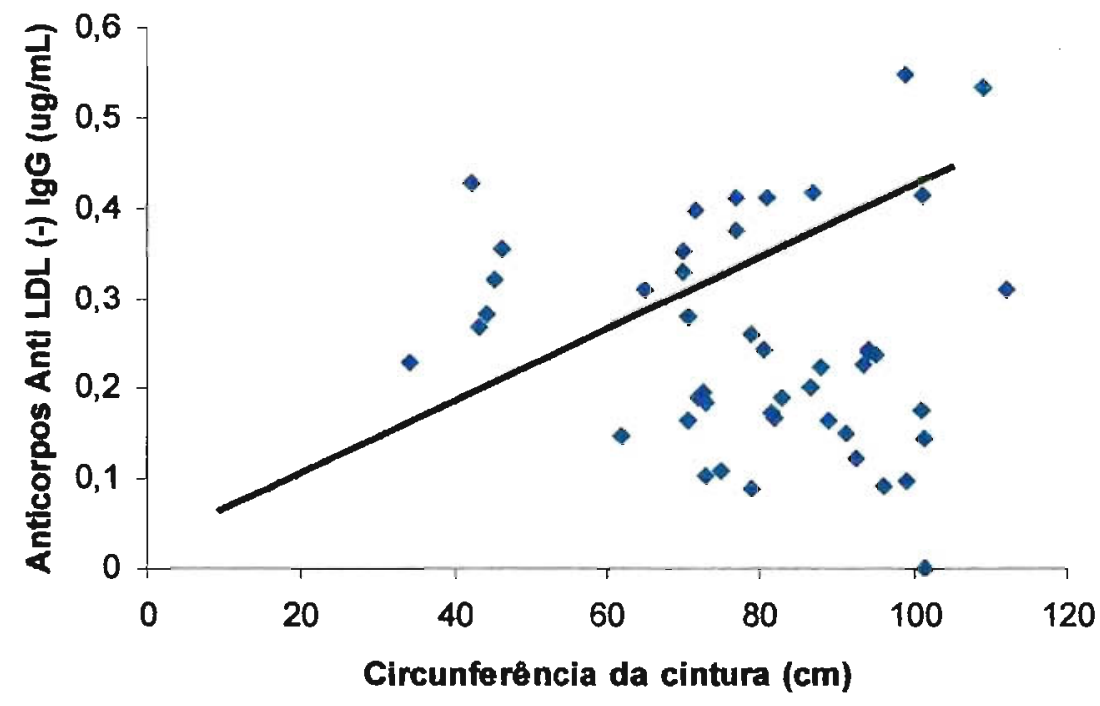

Gráfico 9: Correlação entre anticorpos lgG (ug/mL) anti LDL(-) e circunferência da cintura $(\mathrm{cm})$. 


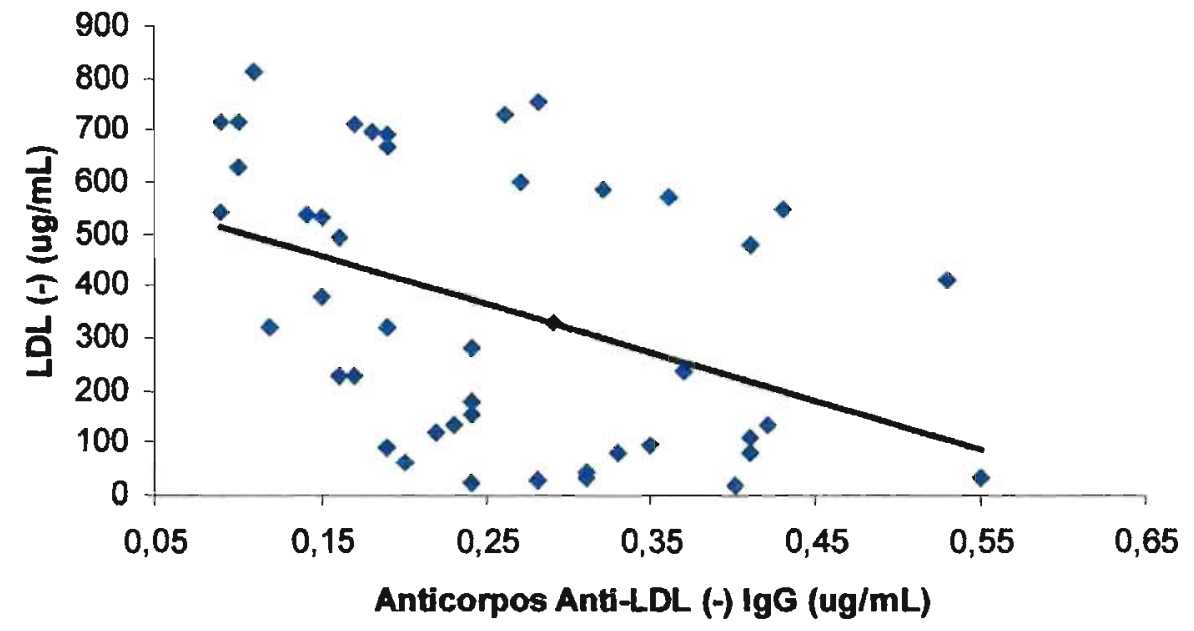

Gráfico 10: Correlação entre LDL(-) $(\mu \mathrm{g} / \mathrm{mL})$ e Anticorpos lgG anti-LDL(-) $(\mu \mathrm{g} / \mathrm{mL})$. 


\section{DISCUSSÃO}

O presente estudo mostrou que a maioria dos pacientes encontrava-se eutrófico segundo O IMC, sendo que, apenas 1 paciente sob DP estava moderadamente desnutrido, 4 pacientes sob hemodiálise e 6 sob diálise peritoneal encontravam-se com sobrepeso e obesidade. Na população geral, este parâmetro está associado com aumento de doença cardiovascular. No entanto, o efeito do sobrepeso ou obesidade no pacientes renais crónicos é paradoxalmente na direção oposta, ou seja, um IMC alto está associado com maior sobrevida. Este fenômeno tem sido referido como "epidemiologia reversa" (Kalantar-Zadeh et al., 2005).

Estudos recentes mostraram que pacientes obesos sob diálise apresentavam menor mortalidade (Wolfe et al., 2000; Leavey et al., 2001; Port et al., 2002; Glanton ot al., 2003; Abbott et al., 2004; Kalantar-Zadeh et al.,2005). Dentre os pacientes sob DP, a quantidade de glicose absorvida da solução de diálise faz com que a desnutrição calórica quase não exista. A desnutrição protéica é mais comum devido à perda de nutrientes pelo dialisado e inibição do apetite (Ruggieri G. et al., 1993).

A vitamina $E$ ( $\alpha$-tocoferol) é um importante antioxidante contra radicais livres causadores de danos à LDL e às membranas biológicas, sendo que os nivei de antioxidantes de pacientes sob diálise são menores devido à diminuição da inge istão oral, restrições dietéticas, interaçōes fármaco-nutriente, perdas durante o processo dialítico, ou, como resultado do aumento da degradação (Latscha, 2001; Ikizler, 2004: Luciak:, 2004 ).

Nosso estudo mostrou que o alfa-tocoferol plasmático estava abaixo da normalidade em todos os pacientes sob diálise peritoneal, nos controles e na maioria dos pacientes hemodialisados. Muitos estudos mostraram concentraçőes similares de alfa-tccoferol plasmático entre controles e hemodialisados (Hultqvist et al., 1997; Rock et al., 1997; Zima et al., 1998; Islam et al., 2000; Roob et al., 2000; Lippa et al., 2000; Clermont et al., 2000; Handelman et al., 2001). Galli et al. (2001) mostraram que na determinação dos niveis de vitamina $E$ em pacientes hemodialisados, é importante corrigir a quantidade de vitamina em relação à quantidade de colestero/triglicerídeos ou fosfolipídios, no plasma ou membranas celulares, respectivamente, porque quando esta 
normalização não é realizada a concentração plasmática de vitamina $E$ de pacientes hemodialisados pode ficar próxima à faixa de referência. Isto foi confirmado em nosso estudo. Além disso, os mesmos autores, sugeriram que os níveis de vitamina $E$ no plasma de pacientes hemodialisados, mesmo dentro da normalidade, poderia ser insuficiente para proteger contra a peroxidaçăo lipidica.

Com relação à vitamina $C$, sua deficiência é também uma complicação no tratamento de pacientes em diálise desde o início da terapia renal substitutiva, pois a principal fonte de vitamina $C$ na dieta provém de alimentos ricos também em potássio, como por exemplo: laranja, morango e brócolis. Desta forma, os alimentos ricos em potássio são quase sempre restritos para pacientes em diálise, pois o processo de diálise remove o potássio com pouca eficiência e a hipercalemia é um dos maiores riscos de morbimortalidade nestes pacientes. Dentro dessas circunstâncias, pode ocorrer baixa ingestão de vitamina C (Ahmed \& Weisberg, 2001). No entanto, este estudo mostrou que a ingestão de vitamina $C$ nos pacientes hemodialisados estava dentro do recomendado.

Estudos mostram que os níveis de vitamina $C$ plasmáticos em pacientes renais crônicos e sob diálise são menores quando comparados aos de individuos saudáveis (Locatelli et al., 2003, Deicher \& Hörl, 2003). A vitamina C plasmática nos pacientes sob diálise é freqüentemente $<10 \mathrm{mM}$, sendo que niveis muito altos de vitamina $\mathrm{C}$ podem ocorrer, pois rins normais excretam vitamina $\mathrm{C}$ quando os niveis plasmáticos excedem $60 \mathrm{mM}$, mas o efeito da diálise sobre a vitamina $\mathrm{C}$ é muito variável (Jackson et al., 1996; Levine et al., 1996). Além disso, as concentraçōes plasmáticas de vitamina C refletem mais adequadamente a ingestão dietética do que o conteúdo nos tecidos e o pool corporal (Neumcke et al., 1999). Isto poderia justificar as concentraçð̃es plasmáticas mais altas desta vitamina observadas no presente trabalho, em relação aos estudos anteriores.

A dislipidemia é um fator de risco independente associado com a aterosclerose e encontrado freqüentemente em pacientes sob diálise. $O$ padrão clássico de dislipidemia nestes pacientes é caracterizado por aumento dos triglicerídeos, diminuiçãa do $\mathrm{HDL}$ colesterol e, geralmente, colesterol total e o LDL-colesterol normal ou apenas um pouco 
elevado o (Wanner \& Quaschning, 2001). Este perfil também foi observado no presente estudo.

Com relação a LDL (-), o úrico estudo já publicado (Ziouzenkova et al.,1 199), demonstrou que os niveis de $\operatorname{LLL}(-)$ nos pacientes sob hemodiálise fram significativamente maiores quando comparados ao grupo de indivíduos saudáveis. Nossos dados sobre LDL(-) foram semelhantes aos do trabalho supracitado e também mostramos, pela primeira vez, que pacientes sob DP apresentam niveis elevados de LDL(-), porém, menores quando comparados aos pacientes HD. De acordo com Tetta et al. 1991, os niveis plasmáticos de LDL minimamente modificada podem ser um parâmetro potencialmente útil para estimar o risco de progressão da aterosclerose associada à inflamação.

Em relação aos enticorpos $\lg G$ anti-LDL(-), este estudo demonstrou que este parâmetro estava aumentado no grupo controle em relação aos pacientes. O papel próou anti-aterogênico dos anticorpos reativos a partículas de LDL modificadas ainda não está completamente elucidado, sendo que as respostas imuno-humoral especificas podem ser moduladas diferentemente quando comparadas com outros processos na aterogênese (Barros et al. 2006). Neste estudo, encontramos um aumento dos níveis de IgG anti-LDL(-) nos controles em relação aos pacientes. Este resultado sugere que os anticorpos IgG anti-LDL(-) podem ter um efeito protetor assim como podem estar associadós com os estágios iniciais da aterosclerose nos pacientes HD e DP.

Os estudos são contraditórios, sendo que alguns indicam efeitos benéficos dos anticorpos anti-LDLox enquanto outros sugerem uma ação pró-aterogênica. Paiker et al., (2000), investigaram os niveis de anticorpos reativos a LDLox como um marcador de aterosclerose em pacientes com hipercolesterolemia familiar (HF) e concluiram que os anticorpos anti-LDLox năo poderiam ser utilizados como marcadores de risco aterosclerótico nestes pacientes. Em pacientes com doença renal crônica, demonstrouse uma associação inversa entre a concentraçăo de anticorpos anti-LDLox e a densidade da parede arterial, o que suportaria o conceito do papel anti-aterogênico destes anticorpos (Shoji et al., 2003).

Os niveis de anticorpos IgG anti-LDL(-) foram avaliados por Barros et al. (2006) em crianças com antecedentes de HF, hipercolesterolêmicos ou 
normocolesterolêmicos, com ou sem doença arterial coronariana relativa aos primeiros estágios, comparando-as a crianças sem antecedentes de HF. Os resultados mostraram que as crianças HF possulam niveis baixos de anticorpos anti-LDL(-) independentemente dos niveis de LDL-colesterol e LDL(-).

Em um estudo recente, Oliveira et al. 2006, determinaram os níveis de LDL eletronegativa e seus auto-anticorpos em pacientes com angina estável e instável comparados a indivíduọs sem doença cardiovascular, demonstrando que as duas variáveis poderiam ser utilizadas como marcadores para avaliar pacientes com alto risco de eventos coronarianos. De qualquer maneira, ainda não está definido qual classe de anticorpos, assim como, se sua ligação com diferentes epítopos nas particulas de LDLox facilitaria ou preveniria o processo aterogênico em adultos (Barros et al., 2006).

A presença de anticorpos anti-LDLox e de imunocomplexos IgG/LDL tem sido demonstrada em pacientes com doença vascular e indivíduos saudáveis (Salonen et al., 1992; Chiesa et al., 1998; Festa et al., 1998; Paiker et al., 2000). Em nosso estudo, os níveis de imunocomplexos no grupo controle foram significativamente maiores comparados aos dos pacientes, sugerindo năo haver relação destes imunocomplexos com o desenvolvimento da aterosclerose.

Holvoet et al. (2001) mostraram que o IMC é uma das variáveis mais envolvidas na concentração de LDLox circulante, embora os estudos que relacionam IMC com LDLox sejam controversos. Porreca et al. (2004) verificaram que o IMC se correlacionou positivamente com a LDLox em mulheres na pós menopausa. Em contraste, Uzun et al. (2004) nāo observaram essa correlação em pacientes obesos antes e depois da cirurgia de reduçăo de estômago. As concentrações de LDLox e seus anticorpos ilão variaram significativamente entre indivíduos com peso normal e sobrepeso numa população japonesa, no entanto, neste mesmo estudo altas concentrações de LDLox foram encontradas em mulheres obesas e indivíduos obesos com hipertensão (Suzuki et al., 2003).

No presente estudo não se observou correlação sigrificante entre os valores de IMC e as concentrações de LDL(-), mas as concentrações plasmáticas dos anticorpös IgG anti-LDL(-) se correlacionaram diretamente com os valores do IMC e da 
circunierência da cintura nos individuos estudados. Tem sido demonstrado que a obesidade está relacionada ao estresse oxidativo (Urakawa et al., 2003) pelo fato do tecido adiposo possuir uma grande atividade metabólica. Embora a gordura abdominal possa estar envolvida com o estresse oxidativo, os estudos associando a gordura abdominal com estresse oxidativo ainda são escassos (Weinbrenner et al., 2006). Alguns estudos que investigaram a redução da gordura corporal mostraram uma diminuição das concentrações plasmáticas de marcadores de estresse oxidativo após a redução de peso através de dieta (Dandona et al., 2001; Vasankari et al., 2001; Davi et al., 2002; Porreca et al., 2004; Raitakari et al., 2004).

Têm-se observado que existe uma associação independente entre sobrepeso, gordura abdominal, marcadores de inflamação e estresse oxidativo (Pihl et al., 2006). Recentemente Weinbrenner et al., (2006) descreveram uma associação independente de circunferéncia da cintura e IMC com a LDLox e PCR (proteína C reativa) e observaram que a medida de da circunferência da cintura estava associada às concentrações de LDLox independentemente do IMC.

A medida da prega cutânea tricipital também retrata a reserva adiposa (Despre's et al., 1991). Observamos neste estudo, que os valores de PCT se correlacionaram diretamente com as concentraçðes plasmáticas dos imunocomplexos e inversamente com as concentrações plasmáticas de LDL(-). Os pacientes hemodialisados apresentaram uma medida de PCT menor comparada aos outros grupos e uma maior concentração de LDL(-), ou seja, o aumento do estresse oxidativo pode estar relacionado com a diminuição da reserva de gordura nestes pacientes. Adicionalmente, foi encontrada uma correlação negativa entre as concentrações de LDL(-) e seus autoanticorpos. Nossos dados sugerem que, diferente da população geral, um maior IMC e uma maior reserva de gordura podem estar relacionados com menor estresse oxidativo em pacientes renais crônicos sob diálise.

O presente estudo foi pioneiro no estudo da relaçāo entre o estado nutricional, avaliado por indicadores antropométricos e LDL(-), seus auto-anticorpos e Imunocomplexos em pacientes renais crônicos, sob hemodiálise e diálise peritoneả. 0 papel da $\operatorname{LDL}(-)$ na aterosclerose tem sido bem descrito na literatura, assim como a relação entre doença cardiovascular em pacientes renais crônicos principalmente sob 
hemodiálise. Um bom estado nutricional poderia influenciar o prognóstico da doença e o bem estar desses pacientes. Apesar de termos encontrado poucos pacientes desnutridos, a desnutrição ainda é bastante prevalente nesta população, o fuue indica a necessidade de outros estudos para se avaliar esta relação, contribuindo assim para um melhor monitoramento da doença. 


\section{CONCLUSÕES}

Com base nos resultados obtidos, pode-se concluir que:

$>$ As concentrações de LDL(-) foram mais elevadas nos pacientes sob hemodiálise comparados àqueles submetidos à diálise peritoneal e ao grupo contrcile.

$>$ Pacientes sob hemodiálise e diálise peritoneal, apresentaram níveis diminuídos de anticorpos IgG anti-LDL(-) em relação ao grupo controle.

$>$ Não houve correlação entre as concentrações plasmáticas de ascorbato e $\alpha$ tocoferol com as de LDL(-), IgG anti-LDL (-) e imunocomplexos.

$>$ Os valores de prega cutânea tricipital (PCT) se correlacionaram diretamente bom as concentrações plasmáticas dos imunocomplexos e inversamente corr as concentrações plasmáticas de LDL(-). As concentrações plașmáticas dos anticorpos anti-LDL(-) se correlacionaram diretamente com os valores do IMC e da circunferência da cintura; 


\section{REFERÊNCIAS BIBLIOGRÁFICAS}

ABBOTT, K.C.; GLANTON, C.W.; TRESPALACIOS, F.C., et al. Body mass index, dialysis modality, and survival: analysis of the United States Renal Data System Dialysis Morbidity and Mortality Wave II Study. Kidney Int Vol. 65, p. 597-605, 2004.

AGUILERA, A.; BAJO, M.A.; DEL PESO, G.; et. al.; True deficiency of antioxiciant vitamins $E$ and $A$ in dialysis patients. Relationship with clinical patterns $;$ of atherosclerosis. Adv. Perit. Dial. Vol. 18, p.206-11, 2002.

AHMED, J.; WEISBERG, L.S.; Hyperkalernia in dialysis patients. Semin Dial , Vol. 14, p. 348-356, 2001.

AMANN, K.; TORNIG, J.; BUZELLO, M.; et al.; Effect of antioxidant therapy with dlalpha-tocopherol on cardiovascular structure in experimental renal failure. Kidney Int. Vol. 62(3), p.877-884, 2002.

AMANN, K.; TORNING, J.; BUZELLO, M.; et. al.; Effect of antioxidant therapy with dlalpha-locopherol on cardiuvascular structure in experimental renal failure. Kidney Int. Vol. 62(3), p. 877-84, 2003.

APOLINÁRIO, E.; FERDEBAR, S.; PEREIRA, E.C.; et al.; Minimally modified (electronegative) LDL- and anti-LDL- autoantibodies in diabetes mellitus and impaired glucose tolerance. Intern. J. of Atherosclerosis, Vol. 1, p. 42-47, 2006.

ASATRYAN, L.; ZIOUZENKOVA, O.; DUNCAN, R.; et al.; Heme and lipid peroxides in hemoglobin-modified low-density lipoprotein mediate cell survival and adaptation to oxidative stress. Blood. Vol. 102(5), p.1732-9, 2003.

AVOGARO, P.; BON, G.B.; CAZZOLATO, G.; Presence of a modified low density lipoprotein in humans. Arteriosclerosis. Vol. 8, p. 79-87, 1988.

BAIARDI, F.; ESPOSTI, E.D.; COCCHI, R.; et. al.; Effects of clinical and individual variables on quality of life in chronic renal failure patients. J Nephrol, Vol. 15, p.61-67, 2002.

BAGARETTI, I.; FURIANI, S.; VETTORETTI, S.; et al.; Role of vitamin E-coated membrane in reducing advanced glycation end products in hemodialysis patients: a pilot study. Blood Purif. Vol. 24(4), p. 369-376, 2006.

BARROS, M.R.; BERTOLAMI, M.C.; ABDALLA, D.S.; et al.; Identification of mildly oxidized low-density lipoprotein (electronegative LDL) and its auto-antibodies IgG in children and adolescents hypercholesterolemic offsprings. Atherosclerosis. Vol.184(1), p.103-7, 2006. 
BECAREVIC, M.; ANDREJEVIC, M.; BONACI-NIKOLIC, B.; et al.; Anti-oxLDL antibodies-marker for arterial thromboses in antiphospholipid syndrome? Clin Lab. Vol. 51(5-6), p. 279-83, 2005.

BELLAZZI, R.; MAGGI, E.; BELLOMO, G.; et. al. Low-density lipoprotein oxidation and antioxidized LDL antibodies in peritoneal dialysis patients; Adv. Perit. Dial. Vol. 9, p.3127, 1993.

BERNITEZ, S.; SANCHEZ-QUESADA, J.L.; LUCERO, L.; et al.; Changes in low-density lipoprotein electronegativity and oxidizability after aerobic exercise are related to the increase in associated non-esterified fatty acids.Atherosclerosis. Vol.160(1), p. 223-32, 2002.

BERNITEZ, S.; SANCHEZ-QUESADA, J.L.; RIBAS, V.; et al. Platelet-activating factor acetylhydrolase is mainly associated with electronegative LDL subfraction. Circulation;Vol.108 p.92-96, 2003.

BERNITEZ, S.; ORDONEZ-LLANOS, J.; FRANCO, M.; et al. Effect of simvastatin in familial hypercholesterolemia on the affinity of charge-differing low-density lipoprotein subfractions to the low-density lipoprotein receptor. Am J Cardiol; Vol. 93 p.414-420, 2004.

BERNITEZ, S.; PEREZ, A.; WAGNER, A.M.; et al.; Electronegative low-density lipoproiein subfraction from type 2 diabetic subjects is proatherogenic and unrelated to glycemic control.Diabetes Metab Res Rev. Vol. 23(1), p. 26-34, 2006.

BERGESIO, F.; MONZANI, G.; CIUTI, R.; et. al.; Autoantibodies agaist LDL in Chronic renal failure: role of renal functions, diet and lipids. Nephron, Vol. 87(2), p.127-33, 2001.

BERLINER JA, TERRITO MC, SEVANIAN A, RAMIN S, KIM JA, BAMSHAD B, ET AL. Minimally modified low density lipoprotein stimulates monocyte endothelial interactions. J Clin Invest Vol. 85, p.1260-6, 1990.

BING, H.; WANG, J.; ZHANG, C.; et al.; Positive correlation between in vivo LDL and LDL immune complexes. Clin. Biochem. Vol. 37 p. 72-75, 2004.

BITTOLO-BON, G.; CAZZOLATO, G.; AVOGARO, P.; Probucol protects low-density lipoproteins from in vitro and in vivo oxidation. Pharmacol. Res. Vol. 29(4), p.337-44, 1994.

BLACKBURN, G.L.; THORNTON, P.A. Nutritional assessment of the hospitalized patients. Med. Clin. North. Am. Vol. 63, p. 1103-1115, 1979.

BOAZ, M.; SMETANA, S.; WEINSTEIN, T.; et. al.; Secondary prevention with antioxidants of cardiovascular disease in endstage renal disease (SPACE): randomised placebo-controlled trial. Lancet. Vol. 7;356(9237), p.1213-8, 2000. 
CADENAS, E.; SIES, H.; Oxidativestress: excited oxygen species and enzyme activity. Adv. Enzyme Regul. Vol. 23, p.217-37, 1985.

CANESTRARI, F.; BUONCRISTIANI, U.; GALLI, F.; Redox state, antioxidative activity and lipid peroxidation in erythrocytes and plasma of chronic arnbulatory peritoneal dialysis patients. Clin. Chim. Acta. Vol. 31;234(1-2), p.127-36, 1995.

CARR, A.; FREI, B.; Does vitamin C act as pro-oxidant under physiological conditions? FASEB J.;Vol.13 p.1007-1024, 1999.

CHANG, Y.H.; ABDALLA, D.S.P.; SEVANIAN, A.; Characterization of cholesterol oxidation products formed by oxidative modification of low density lipoprotein.

Free Rad Biol Med ; Vol. 23 p.202-214, 1997.

CHEN, C.H.; JIANG, T.; YANG, J.H.; et al. Low-density lipoprotein in hypercholesterolemic human plasma induces vascular endothelial cell apoptosis by inhibiting fibroblast growth factor 2 transcription. Circulation; Vol.107 p.2102-2108, 2003.EA

CHIESA, R.; MELISSANO, G.; CASTELLANO, R.; et al.; In search of biological markers of high-risk carotid artery atherosclerosis plaque-enhanced LDL oxidation: Ann. Vasc. Surg. Vol. 12 p. 1-9, 1998.

CLERMONT, G.; LECOUR, S; LAHET,J.; et. al.; Alteration in plasma antioxidant capacities in chronic renal failure and hemodialysis patients: a possible explanation for the increased cardiovascular risk in these patients.Cardiovasc. Res. Vol.18;47(3), p. $618-23,2000$.

DAMASCENO, N.; SEVANIAN, A.; APOLINÁRIO, E.; et al.; Detection of electronega ive low density lipoprotein (LDL-) in plasma andatherosclerotic lesions by monoclcnal antibody-based immunoassays. Clin. Biochem. Vol. 39, p, 28-8, 2006.

DANDONA, P., MOHANTY, P., GHANIM, H., et al.; The suppressive effect of dietary restriction and weight loss in the obese on the generation of reactive oxygen species by leukoc!tes, lipid peroxidation, and protein carbonylation. J Clin Endocrinol Metab Vol.86, p.355-62, 2001.

DAVI, G., GUAGNANO, M.T., CIABATTONI, G., et al.; Platelet activation in obese women: role of inflammation and oxidant stress. JAMA Vol.288, p.2008-14, 2002.

DE CASTEllaRnAU, C.; SANCHEZ-QUESADA, J.L.; BENYTEZ, $\overline{\text { S.; }}$ et al. Electronegative LDL from normolipemic subjects induces IL-8 and monocyte chemotactic protein secretion by human endothelial cells. Arterioscler Thromb Vasc Biol; Vol. 20 p.2281-2287, 2000. 
DEICHER, R.; HÖL, W.H.; Vitamin C in chronic kidney disease and hemodialysis patien is. Kidney Blood Press Res, Vol. 26, p. $100-106,2003$.

DEMUITH, K.; MYARA, I.; CHAPPEY, B.; et al. A cytotoxic electronegative LDL subfraction is present in human plasma. Arterioscler Thromb Vasc Biol; Vol.16 p.773783, 1996.

DESCAMPS-LATSCHA, B.; DRUEKE, T.; WITKO-SARSAT, V.; Dialysis-induced oxidative stress: biological aspects, clinical consequences, and therapy. Semin Dial. Vol. 14(3), p.193-9, 2001.

DESPRÉS, J.; PRUD'HOMME, D., POULIOT, M., et al.; Estimation of deep abđominal adipose-tissue accumulation from simple anthropometric measurements in men. Am J Clin Nutr Vol. 3, p.471-477, 1991.

DRAI, J.; BANNIER, E.; CHAZOT, C.; et. al.; Oxidants and antioxidants in long-term haemodialysis patients. Farmaco, Vol. 56(5-7), p.463-5, 2001.

DRUEKE, T.B.; NGUYEN-KHOA, T.; MASSY, Z.A.; et al.; Role of oxidized low-density lipoprotein in the atherosclerosis of uremia. Kidney Int Suppl. Vol. 78, p. 114-9, 2001.

DURSUN, E.; OZBEN, T.; SULEYMANLAR, G.; et. al. Effect oh hemodialysis on the oxidative stress and antioxidants. Clin. Chem. Lab. Med. Vol. 40(10), p.1009-13, 2002.

ECE, A.; GURKAN, F.; KERVANCIOGLU M.; et al.; Oxidative stress, inflammation and early cardiovascular damage in children with chronic renal failure. Pediatr Nephrol Vol. 21, p. 545-552, 2006.

FESTA, A.; KOPP, H.P.; SCHENTHANER, G.; et al.; Autoantibodies to oxidized Low desity lipoprotein in IDDM are related to metabolic control and microvascular complications. Diabetologia vol.41 p. 350-356, 1998.

FIELDS, M.; Invited commentary: Role of trace elements in coronary heart disease. British Journal of Nutrition, Vol. 81, p. 85-86,1999.

FIORILLO, C.; OLIVIERO, C.; RIZZUTI, G.; et. al.; Oxidative stress and antioxidant defenses in renal patients receiving regular haemodialysis. Clin. Chem. Lab. Med. Vol. 36(3), p.149-53, 1998.

FRISANCHO, A.R.; Anthropometric Standarts for the assessmerit of growth and nutritional status. University of Michigan, p.189,1990.

FUTATSUYAMA, M.; OIWA, T.; KOMATSU, Y.; Correlation between oxidized lowdensity lipoprotein and other factors in patients on peritoneal dialysis. Adv. Perit. Dial. Vol. 18, p.192-4, 2002. 
FUMERON, C.; NGUYEN-KHOA, T.; SALTIEL, C.; et al.; Effects of oral vitamin C supplementation on oxidative stress and inflammation status in haernodialysis patients. Nephrol Dial Transplant Vol. 20(9) p. 1874-9, 2006.

GALLI, F.; ZSUZSA, V.; BALLA, J.; et. al.; Vitamin E, lipid profile, and peroxidation in hemodialysis patients. Kidney Int. Vol. 59, 78, s-, p.148-154, 2001.

GAMBINO, R.; PISU, E.; PAGANO. G.; et al.; Low-density lipoproteins are more electronegatively charged in type 1 than in type 2 diabetes mellitus. Lipids. Vol. 41(6), p. 529-33, 2006.

GLANTON, C.W.; HYPOLITE, I.O.; HSHIE.H, P.B.; et al. ; Factors associated with improved short term survival in obese end stage renal disease patients. Ann Epidemiol, Vol. 13 p. $136-43,2003$.

GLOOR, H.J.; 20 years of peritoneal dialysis in a mid-sized Swiss hospital. Swiss Med. Wkly, 13; Vol. 133(45-46), p. 619-24, 2003.

GOMES, L.F.; ALVES, A.F.; SEVANIAN, A.; et al.; Role of beta2-glycoprotein 1, LjL-, and antioxidant levels in hypercholesterolemic elderly subjects. Antioxid Redox Signal Vol. 6(2), p. $237-44,2004$.

HANDELMAN, G.J.; WALTER, M.F.; ADHIKARLA, R.; et al.; Elevated plasma F2isoprostanes in patientes on long-term hemodialysis. Kidney Int. Vol.59 p. 1960-1966, 2001.

HODIS, H.N.; KRAMSCH, D.M.; AVOGARO, P.; et al.; Biochemical and citotoxic characteristic of an in vivo circulating oxidized low density lipoprotein (LDL-). J Lipid Res 3Vol. !i, p.663-77, 1994.

HOLVOET, P., MERTENS, A., VERHAMME, P., et al.; Circulating oxidized LDL is a useful marker for identifying patients with coronary artery disease. Arterioscler Thromb Vasc Biol Vol.21, p.844-8, 2001.

HORKKO, S.; HUTTUNEN, K.; LAARA, E.; et. al.; Effects of three treatment modes on plasma lipids and lipoproteins in uraemic patients. Ann Med. Vol. 26(4), p. 271-82, 1994.

HORKKO, S.; HUTTUNEN, K.; KORHONEN, T.; et. al.; Decreased clearance of lowdensity lipoprotein in patients with chronic renal failure. Kidney Int. Vol. 45(2), p. 561-70, 1994.

HULTQVIST, M.; HEGBRANT, J.; NILSSON-THORELL, C.; et al.; Plasma concentrations of vitamin $\mathrm{C}$, vitamin $\mathrm{E}$, and/or malondialdeyde as markers of oxygen free radical production during hemodialysis. Cli. Nephrol. Vol. 47, p. 37-46, 1997.

IKIZLER, T.; Role of Nutrition for Cardiovascular risk reduction in chroric Kidney disease patients. Adv. In Chronic. Kidney disease, Vol. 11(2), p.162-171, 2004. 
ISLAM, K.N.; O'BRYNE, D.; DEVARAJ, S.; et. al.; Alpha-tocopherol supplementation decreases the oxidative susceptibility of LDL in renal failure patients on dialysis therapy. Atherosclerosis, Vol.150(1), p.217-24, 2000.

JACKSON, P.; LOUGHREY, C.M.; LIGHTBODY, J.H.; et al. Effect of hemcdialysis on total antioxidant capacity and serum antioxidants in patients with chronic renal failure. Clin Chem; Vol. 41, p. 1135-1138, 1995.

JUNG,H.; CHOI, D.; LEE, S.; Serum Malondialdehyde and Coronary Artery Disease in Hemodialysis Patients. Am. J. Nephrul. Vol. 24, p. 537-542, 2004.

KALANTAR-ZADEH, K.; ABBOTT, K.C.; SALAHUDEEN, A.K.; et al.; Sun,ival advantages of obesity in dialysis patients. Am J Clin Nutr Vol. 81, p. 543-554, 2005.

KALANTAR-ZADEH, K.; KOOPLE, J.D.; KILPATRICK, R.D.; et al.; Association of morbid obesity and weight change over time with cardiovascular survival in hemodialysis population. Am J Kidney Dis, Vol. 46(3), p. 489-500, 2005.

KIM, S.B.; YANG, W.S.; MIN, W.K.; et. al.; Reduced oxidative stress in hypoalbuminemic CAPD patients. Perit. Dial. Int. Vol. 20(3), p.290-4, 2000.

KOBAYASHI, S.; MORIYA, H.; ASO, K.; et. al.; vitamin E-bonded hemodialyzer improves atherosclerosis associated with a rheological improvement of circulating red blood cells. Kidney Int. Vol. 63(5), p. 1881-7, 2003.

KOHLAGEN, J.; KELLY, J.; Prevalence of vascular risk factors and vascular disease in predialysis chronic renal failure. Nephrology(Carlton). Vol. 8(6), p. 274-9; 2003.

KOJO, S.; VITAMIN C: basis metabolism and its function as a index of oxidative stress, Curr. Med. Chem. Vol. 11 p.1041-1064, 2004.

$\mathrm{KOSCH}$, M.; LEVERS, A.; FOBKER, M.; et al.; Dialysis filter type determines the acute effect of haemodialysis on endothelial function and oxidative stress. Nephrol. Dial. Transplant. Vol. 18(7), p. 1370-1375, 2003.

LATSCHA, B.; DRUEKE, T.; SARSAT, V.; Dialysis-induced oxidative stress: Biological Aspects, clinical consequences, and therapy. Seminars in Dialysis, Vol. 14(3), p.193199, 2001.

LEAVEY, S.F.; MCCULLOUGH, K.; HECKING, E.; et al.; Body mass index and mortality in 'healthier' as compared with 'sicker' haemodialysis patients: results from the Dialysis Outcomes and Practice Patterns Study (DOPPS). Nephrol Dial Transplant, Vol. 16, p. 2386-94, 2001.

LEVINE, M.; RUNSEY, S.; WANG, Y.; et al. Vitamin C. In: Ziegler EE, Filer LJ,Jr, eds. Present Knowledge in Nutrition. ILSI Press, Washington, DC: p. 146-159, 1996. 
LIBBY, P.; Atherosclerosis. Natrure V. 420 p. 19-26, 2002.

LIM, P.S.; CHAN, E.C.; LU, T.C.; et. al. Lipophilic antioxidants and iron status in ESRD patients on hemodialysis. Nephron, Vol. 86(4), p. 428-35, 2000.

LIPPA, S.; COLACICCO, F.; BONDANINI, C.; et al.; Plasma levels of coenzyme Q10, vitamin $E$ and lipids in uremic patients on conservative treatment: somie possible biochemical and clinical implications. Cli. Chim. Acta. Vol. 291 p. 81-91, 2000.

LOCATELLI, F.; CANAUD, B.; ECKARDT, K.U.; et al.; Oxidative stress in end-stage renal disease: An emerging threat to patient outcome. Nephrol Dial Transplant, Vol. 18, p. $1272-1280,2003$.

LOHMAN, T.G.; ROCHE, A.F.; MARTCRELL, R.; Anthropometric standartization reference manual. Abridged edition, p.90, 1991.

LOUGHREY, C.M.; YOUNG, I.S.; LIGHTBODY, J.H.; et. al.; Oxidative stress in haemodialysis. QJM, Vol. 87(11), p. 679-83, 1994.

LUCCHI, L.;BERGAMINI, S., BOTTI, B., et al., Influence of Different Hemodialysis membranes on Red Blood cell susceptibility to oxidative stress.Artificial Organs, Vol. 24(1), p. 1-6, 2000.

LUCIAK, M.; Antioxidants in the treatment of patients with renal failure. Rocz. Akad. Med. Biaymst. Vol. 49, p.157-161, 2004.

LUSIS, A.J.; Atherosclerosis. Nature. Vol. 14, p.233-41, 2000.

MACPHEE, C.H.; MOORES, K.E.; BOYD, H.F.; et al. Lipoprotein-associated phospholipase $\mathrm{A} 2$, platelet-activating factor acetylhydrolase, generates two bioactive products during the oxidation of low-density lipoprotein: use of a novel inhibitor. Biochem J.; Vol. 338 p.479-487, 1999.

MARIEB, E.N. Essentials of human anatomy and physiology. 3.ed. Redwood City: Benjamin, Cummings, p.405, 1991.

MAYER, B.; ZITTA, S.; GREILBERGER, J.; et. al.; Effest of hemodialysis on the antioxidative properties of serum. Biochimica et. Biophysica Acta, 1638-267-272, 2003.

MIMIC.-OKA, J.; SIMIC, T.; DJUKANOVIC, L.; et. al.; Alteration in plasma antioxidant capacity in various degrees of chronic renal failure.Clin Nephrol. Vol. 51(4), p.233-41, 1999.

MIRONOVA, M.; VIRELLA, G.; VIRELLA-LOWELL, I.; et al.; Anti-modified LDL antibodies and LDL-containing immune complexes in IDDM patients and healthy controls. Clin. Immunol. Immunopathol. Vol. 85(1), p. 73-82, 1997. 
MOLAVI, B.; MEHTA, J.L.; Oxidative stress in cardiovascular disease: molecular bisis of its deleterious effects, its detection, and therapeutic considerations. Curr. Opin. Cardiol. Vol. 19(5), p.488-93, 2004.

MORO, E.; ALESSANDRINI, P.; ZAMBO, C.; et al.; Is glycation of low density lipopro:eins in patients with Type 2 diabetes mellitus a LDL pre-oxidative condition? Diabet Med Vol. 16(8), p. 663-9, 1999.

MULLER, C.; EISENBRAND, G.; GRADINGER, M.; et. al.; Effects of hemodialysis, dialyser type and iron infusion on oxidative stress in uremic patients. Free Radic. Res. 38(10):1093-100, 2004.

MYDLIK, M.; DERZSIOVA, K.; RACZ, O.; et al. Vitamin E as an antioxidant agent in CAPD patients. Int. J. Artif. Organs., Vol. 25(5), p. 373-8, 2002.

NEUMCKE, I.; SCHNEIDER, B., FANDREY, J.; et al.; Effects of pro- and antioxidative compounds on renal production of erythropoietin. Endocrirology, Vol. 140 p. 641-645, 1999.

NOUROOZ-ZADEH, J.; Effect of dialysis on oxidative stress in uraemia. Redox Rep. Vol. 4(1-2), p.17-22, 1999.

O'BYRNE, D.; DEVARAJ, S.; ISLAM, K. et. al.; Low-density lipoprotein (LDL)-induced monocyte-endothelial cell adhesion, soluble cell adhesion molecules, and autoantibodies to oxidized-LDL in chronic renal failure patients on dialysis therapy. Metabolism. Vol. 50(2), p. 207-15, 2001.

OLIVEIRA, J.A.; SEVANIAN, A.; RODRIGUES, R.J.; et al.; Minimally modified electronegative LDL and its autoantibodies in acute and chronic coronary syndromes. Clin Biochem Vol. 39(7), p. 708-14, 2006.

PASTOR, M.C.; SIERRA, C.; BONAL, J.; et. al.; Serum and erythrocyte tocopherol in uremic patients: effect of hemodialysis versus peritoneal dialysis. Am. J. Neprol. Vol. 13(4), p. 238-43, 1993.

PECOITS-FILHO, R.; LINDHOLM, B.; STENVINKEL, P.; The malnutrition, inflammation, and atherosclerosis(MIA) syndrome-The heart of the matter; Nephrol. Dial. Transplant. Suppl. Vol.11, p.28-31, 2002.

PAIKERJ.E.; RAAL, F.J.; VON ARB, M.; Auto-antibodies against LDL as a markei of coronary artery disease in patients with familial hypercholesterolaemia. Ann. Clin. Biochem. Vol.37 p. 174-178, 2000. 
PIHL, E., ZILMER, K., KULLISAAR, T., et al.; Atherogenic inflammatory and oxidative stress markers in relation to overweight values in male former athletes.Int Obes(Lond) Vol. 30(1), p. 141-6, 2006.

PEREIRA, E.C.; BERTOLAMI, M.C.; FALUDI, A.A.; et al.; Antioxidant effect of simvastatin is not enhanced by its association with alpha-tocopherol in hypercholesterolemic patients. Free Radic Biol Med Vol. 37(9), p. 1440-8, 2004.

PRAKASH, M.; UPADHYA, S.; PRABHU, R.; Protein thiol oxidation and lipid peroxidation in patients with uraemia. Scand. J. Clin. Lab. Invest. Vol. 64(6), p. 599-604, 2004.

PRICHARDS. Risk factors for coronary artery disease in patients with renal failure. Am. J. Med Sci. Vol. 325(4), p. 209-23, 2003.

PRYOR, W.A.; VitaminEand heart disease: basic science to clinical intervention trials, Free Rad. Biol. Med. Vol. 28 p.141-164, 2000.

PORT, F.K.; ASHBY, V.B.; DHINGRA, R.K.; et al.; Dialysis dose and body mass index are strongly associated with survival in hemodialysis patients. J Am Soc Nephrol, Vol. 13, p. $1061-6,2002$.

PORRECA, E., DI FEBBO, C., MORETTA, V., et al.; Circulating leptin is associated i, ith oxidized LDL in postmenopausal women. Atherosclerosis Vol.175, p.139-43, 2004.

RADULESCO, L.; STANCU, C.; ANTOHE, F.; Antibodies against human oxidized luwdensity lipoprotein(LDL) as markers for human plasma modified lipoproteins. Med Sci Monit, Vol. 10(7), p. 207-214, 2004.

REDGIRAVE, T. G., ROBERTS, D. C., WEST, C. E.: Separation of plasma lipoproteins by den:sity-gradient ultracentrifugation. Anal Biochem Vol. 65 (1-2), p. 42-9, 1975.

RAITAKARI, M., ILVONEN, T., AHOTUPA, M., et al.; Weight reduction with verylowcaloric diet and endothelial function in overweight adults: role of plasma glucose. Arterio:scler Thromb Vasc Biol Vol. 24, p.124-8, 2004.

RETSKY, K.L.; CHEN, K.; ZEIND, J.; et al.; Inhibition of copper-induced LDL oxidation by vitarnin $C$ is associated with decreased copper-binding to LDL and 2-oxo-histidine formation. Free Radic. Biol. Med. Vol. 26(1-2), p. 90-98, 1999.

RIELLA, M.C., MARTINS, C.; Nutrição e hemodiálise.In:Riella,M.C.;Martins,C. Guanabara Koogan S.A.(Ed.).Nutrição e o Rim.Rio de Janeiro, p.114-130, 2003.

RIGLA, M.; SANCHEZ-QUESADA, J.L.; ORDONEZ-LLANOS, J.; et al.; Effect of physical exercise on lipoprotein (a) and low-density lipoprotein modifications in type 1 and type 2 diabetic patients. Metabolism. Vol. 49(5), p. 640-7, 2000. 
ROCK, C.L.; JAHNKE, M.G.; GORENFL.O, D.W; et al; Racial grcup differences in plasma concentrations of antioxidant vitamin and carotenoids in hemodialysis patients. Am. J. Clin. Nutr. Vol. 65, p. 844-850, 1997.

ROOB, C.L.; KHOSCHSORUR, G.; IIRAN, A.; et al.; Vitamin E attenuates oxida ve stress induced by intravenous iron in patients on hemodialysis. J. Ain.Soc. Nephrol. 'ol. 11 , p. $539-549,2000$.

RUGGIERI, G.; SPINELLI, C.; D'ADAMO, G.; et al.; Nutritional status of CAPD patients in Lazio. Riv. Eur. Sci. Med. Farmacol. Vol. 15(3-4), p. 149-53, 1993.

SALONIEN J.T.; YLA-HERTTUALA, S.; YAMAMOTO, R.; et al.; Autoantibody against oxidized LDL and progression of carotid atherosclerosis. Lancet Vol. 339 p. 883-886, 1992.

SANCHEZ-QUESADA, J.L.; PEREZ, A.; CAIXAS, A.; et al.; Effect of glycemic optimization on electronegative low-density lipoprotein in diabetes: relation to nonenzymatic glycosylation and oxidative modification. J Clin Endocrinol Metab Vol.86, p.3243-3249, 2001.

SANCHEZ-QUESADA, J.L.; BENITEZ, S.; FRANCO, M.; et al.; Density distribution of electronegative LDL (LDL(-)) in normolipemic and hyperlipemic subjects. 'J Lipid Res. Vol. 43, p.699-705, 2002.

SANCHEZ-QUESADA, J.L.; CAMACHO, M.; ANTON, R.; et al. Electronegative LDL of FH subjects: chemical characterization and induction of chemokine release from human endothelial cells. Atherosclerosis; Vol.166 p. 261-270, 2003.

SANCHEZ-QUESADA, J.L.; BENITEZ, S.; ORDONEZ-LLANOS, J.;Electronegative lowdensity lipoprotein Current Opinion in Lipidology; Vol.15 p.329-335, 2004.

SANCHEZ-QUESADA, J.L.; BERNITEZ, S.; PEREZ, A.; et al.; The inflammatory properties of electronegative low-density lipoprotein from type 1 diabetic patients are related to increased platelet-activating factor acetylhydrolase activity. Diabetologia. Vol. 48(10), p. 2162-9, 2005.

SASAKI, M.; Development of vitamin E-modified polysulfone membrane dialyzers. J. Artif. Organs. Vol. 99(1), p. 50-60, 2006.

SATOH, M.; YAMASAKI, Y.; NAGAKE, J.; et. al.; Oxidative stress is reduced by the long-term use of vitamin E-coated dialysis filters. Kidney Int. Vol. 59(5), p. 1943-50, 2001.

SEVANIAN, A.; HODIS, H.N.; HWANG, J.; et al. Characterization of endothelial cell injury by cholesterol oxidation products found in oxidized LDL. J Lipid Res; Vol.36 p.1971-1986, 1995. 
SEVANIAN, A.; BITTOLO-BON, G., CAZZOLATO, G., et al. Electronegative LDL is a lipid hydroperoxide-enriched circulating lipoprotein. J Lipid Res Vol. 38 p.419-428, 1997.

SHOJI, T.; KIMOTO, E.; EMOTO, M.; The association of antibodies against oxidized low-density lipoprotein with atherosclerosis in hemodialysis patients. Kidney Int. Suppl. Vol. 84, p.128-30, 2003.

SNIDERMAN, A.D. Applying apoB to the diagnosis and therapy of the atherogenic dyslipoproteinemias: a clinical diagnostic algorithm. Curr. Opin Lipidol. Vol. 15(4), p. 433-8. 2004.

SNIVELY, C.S.; GUTIERREZ,C.; Chronic Kidney disease: prevention and tratament of common complications. Am. Fam. Physician. Vol.15;70(10), p. 1921-8, 2004.

SOMMERBURG; SOSTMANN, K.; GRUNE, T.; et al.; Oxidative stress in hemodialysis patients treated with a dialysis membrane which has alpha-tocopherol bonded to its surface.. Biofactors Vol. 10(2-3), p. 121-124, 1999.

SONOKI, K.; IWASE, M.; IINO, K.; et al. Atherogenic role of lysophosphatidylcholine in low-density lipoprotein modified by phospholipase $\mathrm{A} 2$ and in diabetic patients: protection by nitric oxide donor. Metabolism; Vol. 52 p.308-314., 2003.

STAFFORINI, D.M.; MCINTYRE, T.M.; ZIMMERMAN, G.A; et al. Platelet-activating factor acetylhydrolases. J Biol Chem; Vol.272 p.17895-17898, 1997.

SURIYAPHOL, P.; FENSKE, D.; ZA“ HRINGER, U.; et al. Enzymaticaily modified nonoxidized low-density lipoprotein induces interleukin-8 in human endothelial cells: role of free fatty acids. Circulation; Vol.106 p.2581-2587, 2002.

SUZUKI, K., ITO, Y., OCHIAI, J., et al.; Relationship between obesity and serum markers of oxidative stress and inflammation in Japanese. Asian Pac J Cancer Prev Vol. 4, p.259-66, 2003.

TAI, M.H.; KUO, S.M.; LIANG, H.T.; et al.; Modulation of angiogenic processes in cultured endothelial cells by low density lipoproteins subfractions from patients with familial hypercholesterolemia. Atherosclerosis Vol. 86(2), p.448-57, 2006.

TERTOV, V.V.; SOBENIN, I.A.; OREKHOV, A.N.; et al.; Characteristics of low density lipoprotein isolated from circulating immune complexes. Atherosclerosis Vol. 122, p. 191-199, 1996.

TETTA, C.; SEGOLONI, G.; MARIANO, F.; et al.; Leukocyte-derived mediators and biocompatibility. Nephrol Dial Transplant Vol. 6(2), p. 24-30, 1991. 
THIRD REPORT OF THE NATIONAL CHOLESTEROL EDUCATION PROGRAM (NCEP) expert panel on detection, evaluation, and treatment of high blood cholesterol in adults (Adult Treatment Panel III). Fin lal report. Circulation. Vol.106 p. 3143-3421, 2(:02.

THURNHAN, D.I.; SMITH, E.; FLORA, P.S.; Concurrent liquid-chromatographic ass y of retinol, $\alpha$-tocoferol, $\beta$-carotene, $\alpha$-carotene, lycopene and $\beta$-cryptoxanthin. Clin. ChIm., Vol. 34, p. 337-343, 1988.

TINAHONE, F.J.; GOMEZ-ZUMAQUERO, J.M.; GARRIDO-SANCHEZ, L.; et al.; Influence of age and sex on levels of anti-oxidized LDL antibodies and anti-LDL immune complexes in the general population. J Lipid Res. Vol. 46(3), p. 452-7, 2005.

TSAO, C.S., SALIMI, S.L., Ultramicromethod for the measurement of ascorbic acid in plasma and white blood cells by hight-performance liquid chromatography with electrochemical. J. chromatogr., Vol. 224, p. 477, 1981.

TSIMI.-HODIMOS, V.; KARABINA, S.A.; TAMBAKI, A.P.; et al. Altered distribution of platelet-activating factor-acetylhydrolase activity between $L D L$ and $H D L$ as a function of the severity of hypercholesterolemia. J Lipid Res; Vol. 43 p.256-263, 2002.

USBERTI, M.; GERARDI, G.M.; GAZZOTTI, R.M.; et. al.; Oxidativé stress and cardiovascular disease in dialyzed patients. Nepron, Vol. 91(1), p. 25-33, 2002.

URSINI, F.; SEVANIAN, A.; Postprandial oxidative stress. Biol Chem;Vol. 383, (3-4) p.599-605, 2002.

URSINI, F.; DAVIES, K.J.; MAIORINO, M.; et al.; Atherosclerosis: another protein misfolding disease?. Trends Mol Med. Vol. 8(8), p.370-4, 2002.

URAKAWA, H., KATSUKI, A., SUMIDA, Y., et al.; Oxidative stress is associated with adiposity and insulin resistance in men. $J$ Clin Endocrinol Metab Vol.88, p. 4673-6, 2003.

UZUN, H., ZENGIN, K., TASKIN, M., et al.; Changes in leptin, plasminogen activator factor and oxidative stress in morbidly obese patients following open and laparoscopic Swedish adjustable gastric banding. Obes Surg Vol.14, p.659-65, 2004.

VALKO, M.; RHODES, C.J.; MONCOLA, J.; et al.; Free radicals, metals and antioxidants in oxidative stress-induced cancer. Chemico-Biological Interactions. Int J Biochem Cell Biol. Vol. 39(1), p. 44-84, 2006.

VALTIN, H.; SCHAEFER, J.; Renal Function, $3^{a}$ ed. Boston:Litlle, Brown and Company, 1p. 1-209, 1995. 
VAN, T. L.; DE GRAAF, J.; HAK-LEMMERS, H.; et. al. Increased levels of low-density lipoprotein oxidation in patients with familial hypercholesterolemia and in end-stage renal disease patients on hemodialysis. Lab Invest. Vol. 83(1), p.13-21, 2003.

VASANKARI, T., FOGELHOLM, M., KUKKONEN-HARJULA, K., et al.; Reduced oxidized low-density lipoprotein after weight reduction in obese premenopausal women. Int J Obes Relat Metab Disord Vol. 25, p.205, 2001.

VAZIRI, N., Roles of oxidative stress and antioxidant therapy in Chronic kidney Disease and Hypertension. Curr. Opin. Nephrol. Hypertens. Vol.13, p.93-99, 2004.

VEDIE, B.; JEUNEMAITRE, X.; MEGNIEN, J.L.; et al.; Charge heterogeneity of LDL in asymptomatic hypercholesterolemic men is related to lipid parameters and variations in the ApoB and Cill genes. Arterioscler Thromb Vasc Biol Vol. 18(11), p. 1780-9, 1998.

YANG, C.Y.; RAYA, J.L.; CHEN, H.H.; et al. Isolation, characterization, and functional assessment of oxidatively modified subfractions of circulating low-density lipoproteins. Arterioscler Thromb Vasc Biol; V'ol. 23 p.1083-1090, 2003.

YANO, M.; INOUE, M.; MAEHATA, E.; et al.; Increased electronegative charge of serum low-density lipoprotein in patients with diabetes mellitus.Clin Chim Acta. Vol. 340(1-2), p. 93-8, 2004.

YAO, Q.; AXELSSON, J.; HEIMBURGUER, O., STENVINKEL P, LINDHOLM B. Systemic inflammation in dialisysis patients with end-stage renal disease: causes and consequences. Minerva Urol Nephrol. Vol. 56, p. 237-48, 2004.

YOUNG, L.S.; MCENENY, J.; Lipoprotein oxidation and atherosclerose. Biochemical Society Transactions, Vol. 29, p.358-362; 2001.

ZIMA, T.; JANEBOVA, M.; NEMECEK, K.; et al.; Retinol and alpha-tocopherol in hemodialysis patients. Ren, Fail. Vol. 20, p. 505-512, 1998.

ZIOUZENKOVA, O.; ASATRYAN, L.; SEVANIAN, A.; Oxidative stress resulting from hemolysis and formation of catalytically active hemoglobin protective strategies. Int. $\mathrm{J}$. Clin. Pharmacol. Ther. Vol. 37(3), p.125-32, 1999.

ZIOUNZENKOVA, O.; ASATRYAN, L.; AKMAL, M.; et al.; Oxidative Cross-linking of ApoB100 and Hemoglobin Results in Low Density Lipoprotein Modification in B rod, relevance to atherogenesis caused by Hemodialysis. Am. Soci. Bio. Chem.;Vol:274, N.27, p.18916-18924, 1999. 
ZIOUNZENKOVA, O.; SEVANIAN, A.; Oxidative modification of low-derisity lipoprotein(LDL) in HD patients: role of in eletronegative LDL formation. Blood Purif. //ol. 8(3), p.169-76, 2000.

ZIOUNZENKOVA, O.; ASATRYAN, L.; TETTE,C.; et. al. Oxidative stress during Ex vivo Hemodialysis procedure utilizing antioxidants. Free Radical Biology \& Medicine, Vol. 33, N.2, p.248-258, 2002.

ZIOUZENKOVA, O.; ASATRYAN, L.; SAHADY, D.; et al. Dual roles for lipolysis and oxidation in peroxisome proliferation-activator receptor responses to electronegative low density lipoprotein. J Biol Chem; Vol. 278 p.39874-39881, 2003.

ZWOLINSKA, D.; GRZESZCZAK, W.; SZCZEPANSKA, M.; et al.; Vitamins A, E and C as non-enzymatic antioxidants and their relation to lipid peroxidation in children with chronic renal failure. Nephron Clin Pract. Vol. 103(1), p.12-8, 2006.

WANNER, C.; QUASCHNING, T.; Dyslipidemia and renal disease: phatogenesis and clinical consequences. Curr. Opin. Nephrol. Hypertens. Vol.10, p.195-201, 2001.

WEINBRENNER, T., SCHRÖDER, H., ESCURRIOL, V., et al.; Circulating oxidized LDL is associated with increased waist circumference independent of body mass index in men and women. Clin Nutr Vol. 83, p.30-5, 2006.

WESTHUYZEN,J.; SALTISSI, D.; HEALY, H.Oxidation of low density lipoprotein in hemodialysis patients: effect of dialysis and comparasion with matched controls. Atherosclerosis, Vol. 21;129(2), p.199-205. 1997.

WIECZOROWSKA-TOBIS, K.; BREBOROWICZ, A.; WITOWSKI, J.; et. al.; Effect of vitamin $E$ on peroxidation and permeability of the peritoneum. J. Physiol. Pharmacol. Vol. 47(3), p.535-43, 1996.

WOLFE, R.A.; ASHBY, V.B.; DAUGIRDAS, J.T.; AGODOA, L.Y.; JONES, C.A.; PORT, F.K.; Body size, dose of hemodialysis, and mortality. Am J Kidney Dis, Vol. 35, p. 80-8, 2000.

WORLD HEALTH ORGANIZATION. Physical status: the use and interpretarion of anthropometry. Geneva: WHO, p. 362-374, 1997. 


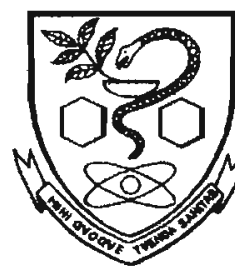

UNIVERSIDADE DE SÃO PAULO

Faculdade de Ciências Farmacêuticas

Secretaria de Pós-Graduação

\section{Informações para os Membros de Bancas Julgadoras de Mestrado/Doutorado}

1. O candidato fará uma apresentação oral do seu trabalho, com duração máxima de trinta minutos.

2. Os membros da banca farão a argüição oral. Cada examinador disporá, no máximo, de trinta minutos para argüir o candidato, exclusivamente sobre o tema do trabalho apresentado, e o candidato disporá de trinta minutos para sua resposta.

2.1 Com a devida anuência das partes (examinador e candidato), é facultada a argüição na forma de diálogo em até sessenta minutos por examinador.

3. A sessão de defesa será aberta ao público.

4. Terminada a argüição por todos os membros da banca, a mesma se reunirá reservadamente e expressará na ata (relatório de defesa) a aprovação ou reprovação do candidato, baseando-se no trabalho escrito e na argüição.

4.1 Caso algum membro da banca reprove o candidato, a Comissão Julgadora deverá emitir um parecer a ser escrito em campo exclusivamente indicado na ata.

4.2 Será considerado aprovado o aluno que obtiver aprovação por unanimidade ou pela maioria da banca.

5. Dúvidas poderão ser esclarecidas junto à Secretaria de PósGraduação: pgfarma@usp.br, (11) 30913621.

São Paulo, 18 de março de 2005.

Profa. Dra. Bernadette D. G. M. Franco

Presidente da CPG/FCF/USP 

Comitê de Ética em Pesquisa - CEP

Ilmo(a). $\operatorname{Sr}(a)$.

Julie Calixto Lobo

Orientador: Prof. Dulcineia Saes Parra Abdalla

I $B B C$

Prezado(a) Senhor(a).

Vimos informar que o Comitê de Ética em Pesquisa da IFCF/USP, em reuniã:

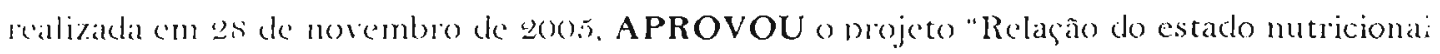
com a peroxiclasion lipíclica em pacientes renais crônicos sob tratamento conservador, hemodiálise e diálise peritoneal" (Protocolo CEP n" 9q4) apresentado por Vossa Senhoria.

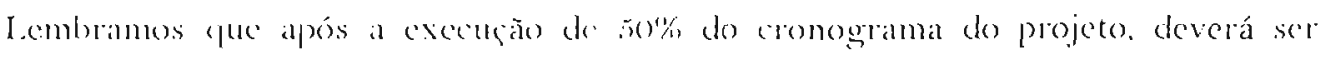
apresentado um relatório parcial, de acordo com o Artigo I 8 - item C, da Portaria FCI:$111 / 97$

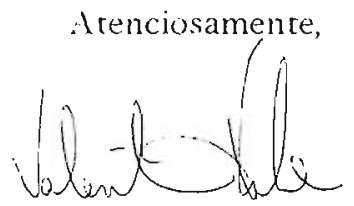

Prof ${ }^{u}$. Dr. Valentina Porta

Coordenadora do Comitê de Ética

em Pesquisa da FCF/USP 